(Aus dem zoologisch-vergleichend-anatomischen Institut der Universität Zürich.)

\title{
Untersuchungen zur Physiologie des Nervensystems bei Pulmonaten.
}

II.

Tonas und Erregbarkeit. Die regulierende Funktion des Cerebralganglion.

Von

\section{Hermann Jordan.}

(Mit 1 Textfigur.)

Inhaltsverzeichnis.

I. Experimenteller Teil . . . . . . . . . . . . . . . . . 534

A. Tonus und Erregbarkeit. . . . . . . . . . . . 534

B. Regulierung der Erregbarkeit durch die Ganglien . . . . . . . . 551

1. Das Pedalganglion. . . . . . . . . . . 551

2. Das Cerebralganglion. . . . . . . . . . . . 557

a) Der unmittelbare Einfluss des Cerebralganglion auf Erregbarkeit and Reflexe . . . . . . . . . . . . . 557

b) Beeinflusst das Cerebralganglion den Tonus? . . . . . . 559

c) Wie arbeiten Tonus und Cerebralganglion zusammen? . . 565

d) Die regulatorische Funktion des Cerebralganglion je nach . seinem Zustande . . . . . . . . . . . . . 570

II. Ökonomische Betrachtungsweise der Ergebnisse. . . . . . . . 575

A. Das Problem der normalen Lokomotion. . . . . . . . . . 575

B. Die Regulierung der Reflexe und der Lokomotion durch das Zentralnervensystem . . . . . . . . . . . . . . . . . . . 581

C. Anwendung der Versuchsergebnisse auf einige Tatsachen, die an sich nicht Gegenstand dieser Untersuchung waren . . . . . . 585

III. Kausale Betrachtungsweise der Ergebnisse . . . . . . . . . . . . . 588

A. Was lernen wir über das Wesen des Tonus? . . . . . . . . 588

B. Das Gesetz vom Energieausgleich und die Regulierung der Erregbarkeit durch die Ganglien . . . . . . . . . . . . . . . . . 594

E. Pflüger, Archì für Physiologie. Bd. 110. 
In einer ersten Mitteilung ${ }^{1}$ ) babe ich mich bemüht, einige Aufklärung über diejenigen Einrichtungen zu geben, denen bei der Schnecke eine überaus zweckmässige Regulierung des Muskelzustandes zuzuschreiben ist. Der weitere Gang der Untersuchung war gegeben.

Den Organismus als Maschine auffassend, ist es unsere Aufgabe, seine Leistungen, also alle $\mathrm{ihm}$ möglichen Zustandsänderungen, in ihrem Wesen verstehen zu lernen: um einen möglichst grossen Teil des Geschehens innerhalb des tierischen Organismus beschreiben zu können. So musste auf ein Studium des Zustandes ein Studium der Bewegungen folgen; und zwar für diesmal ein Studium der Einzelbew egungen. Aus den Resultaten der Analyse von aktiver und passiver Zustandsänderung wird dann späterhin durch Synthese der Gesamtorganismus in seinen Funktionen zu rekonstruieren sein.

\section{Experimenteller Teil.}

\section{A. Tonus und Erregbarkeit.}

Wenn auch schon Tatsachen bekannt waren, die dafür sprachen, dass ein (glatter) Muskel um so leichter erregbar, desto höher sein Dehnungsgrad ist, so ist es doch meines Wissens zuerst v. Uexküll ${ }^{2}$ ) gewesen, der den Satz aufgestellt hat: Der Tonus ist für einen Muskel die Schwelle der Erregbarkeit. Nicht nur, sagt dieser Forscher, wird ein gedehnter Muskel auf geringere Reize ansprechen, sondern es wird innerhalb eines Nervennetzes die Erregung stets dem gedehnten Muskel zufliessen (1. S. 3 S.-A. 2. S. 40). Der Beweis wurde unter anderem folgendermassen erbracht: v. Uexküll entfernt einem Schlangenstern alle Arme bis auf einen einzigen. An der Stelle, die dem Anwachsungspunkte jenes Armes gegenüberliegt, also von ihm durch den Durchmesser der Mundscheibe getrennt, wird der "zentrale" Nervenring durchschnitten. Befindet sich nun der Arm in horizontaler Lage, und reizt man einen Teil des Ringes, so kontrahiert sich stets diejenige Muskelpartie, die dem Reizorte

1) Pflüger's Arch. Bd. 106 S. 189-228.

2) Ich werde, was die Resultate und Ansichten v. Uexküll's betrifft, nur auf seine zusammenfassenden Arbeiten verweisen. Es bedeute 1: Die ersten Ursachen des Rhythmus in der Tierreihe. Ergebnisse d. Physiol. Jahrg. 3 Abt. 2. J. F. Bergmann, Wiesbaden 1904; - 2: Leitfaden in das Studium der experimentellen Biologie der Wassertiere. J. F. Bergmann, Wiesbaden 1905. 
zugekehrt ist. Der Arm schlägt dem Reizorte zu. Anders wenn fler Stern so aufgehängt ist, dass der Arm - in der Ebene des Tieres - herabhängt. Nunmehr schlägt, wo auch immer gereizt wird, der Arm nach oben: Der gedehnte Muskel zieht die Erregung an, der kontrahierte aber ist gegen sie refraktär. Hieraus ergibt sich einmal die Möglichkeit einer Normallokomotion für den Schlangenstern, und damit vielleicht auch für alle (niederen) Tiere, die skeletttragende, um ein Gelenk schwingende Gehwerkzeuge besitzen. Ferner erinnern wir uns, dass B e th e u. a. fand, dass für ein System I. Ordnung, welches lediglich aus Rezeptoren, Nervennetz und Effektoren besteht, es nur der Kenntnis der refraktären Periode bedürfe, um die Lokomotion (Rhythmen) der in Betracht kommenden Tiere (beispielsweise einer Meduse) erklären zu können.

Diese Verhältnisse scheinen ja verständlich genug zu sein: Die Organismen sind Produkte einer uns dem Wesen nach unbekannten Anpassung; Anpassung insofern, als zwischen der Organisation und den äusseren Bedingungen eine derartige Beziehung besteht, dass wir sie in kausalen Zusammenhang zu bringen gezwungen sind. Dem Tiere, welchem die Aufgabe zufällt, seinen Platz im Kampf ums Dasein zu behaupten, stellen sich die äusseren Bedingungen in der Regel als Schwierigkeiten, ja, man möchte sagen, als "Probleme" in . Ren Weg, wenn man nur nicht in Versuchung wäre, "Problem" als Aufgabe des Intellektes zu betrachten. Wir finden nun bei den Organismen diese "Probleme" gelöst, dergestalt, dass die, vor Erreichung des in Frage stehenden Zieles vorhandene Organisation als Material, "Anpassungsmaterial" dient. Das einmal Erreichte aber gehorcht den nämlichen Gesetzen, nach denen auch wir uns zu richten haben, wenn wir eine Maschine bauen wollen. Gerade dadurch wird ja das Studium der tierischen Organisation so anziehend und lehrreich, dass die "Natur" in ganz der gleichen Weise zu arbeiten gezwungen ist als wir: analoge Probleme, gleiche Gesetze. Kennen lehren aber kann uns dieses Arbeiten der Natur nur das Studium des Werdens der Funktion, das vergleichende Studium!

Kommen wir zu unserem Falle: Dem Organismus steht vor allem zu seiner Lokomotion als Material zur Verfügung: das kontraktile Plasma. Nachdem das Tier einmal feste Gestalt angenommen hat, kann man die Eigenschaften dieses kontraktilen Plasma (nun schon Muskel zu nennen), wie folgt, definieren: Fähigkeit zur Kraftentfaltung in einer Richtung mit beschränkter Ausdehnung. Also 
die nämlichen Verhältnisse wie etwa bei einer Kolbendampfmaschineund damit das nämliche Problem: vor allem einer Gegenwirkung, da durch eime solche die Ausgangslage wieder erreicht werden muss, die ihrerseits neuerliche Kraftentfaltung ermöglicht. Hierzu muss aber abwechselnd Aktion und Gegenaktion lahmgelegt werden: exzentrische Steuerung - refraktäres Stadium. Das Kontraktionsvermögen des Muskels ist nicht Gegenstand unserer "ökonomischen" (biologischen - v. Uexküll) Betrachtungsweise. Es bleibt das refraktäre Stadium, die Steuerung in der Lokomotion der (niederen) Tiere, als eine der ersten Fundamentalfragen.

Wir haben gesehen (Mitteilung I), dass diese Frage, als solche, für die Schnecke Gültigkeit hat: Die Iokomotorischen Wellen im Fusse stellen eine rhythmische Bewegung dar, die, in vieler Beziehung der Medusenbewegung ähnlich, doch andrerseits durch das wellenartige Wandern entsprechender Erregungsphasen, wesentlich komplizierter ist.

Wir werden also vor allem zu untersuchen haben, ob auch bei der Schnecke "der Tonus die Schwelle der Erregbarkeit" sei, d. h. vorab, ob ein Muskel, der im Zustande geringen Tonus sich befindet, auf geringere Reize hin anspricht. Ehe wir jedoch an das Experiment gehen, sollten wir uns mehr Klarheit über dasjenige zu verschaffen suchen, was wir von ihm zu erwarten haben. Ich bitte vorab, annehmen zu dürfen, obige Frage sei in bejahendem Sinne entsehieden. Versuchen wir, uns daraufhin ein Bild von der Lokomotion zu machen, um zu sehen, ob jenes Gesetz zur Erklärung der Lokomotion ausreicht:

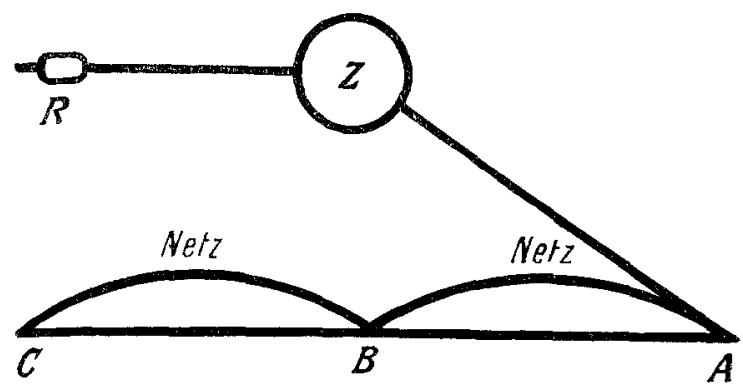

Die Erregung treffe bei $A$ auf den Muskel. Die Kontraktion beginnt an einer bestimmten Stelle, und da der ganze Muskel $A C$ gleichen Tonus aufweist, so müssen wir annehmen, dass sie da 
beginnt, wo die Erregung den Muskel am unmittelbarsten trifft, also bei $A$. Es erfolgt Kontraktion $A B$, wobei die Strecke $B O$, durch das aus $A B$ ausgepresste Blut, gedehnt wird. Nun wird schon die durch Leitungswiderstand (dem wir es ja zuschreiben, dass $A B$ sich allein kontrahiert hat) abgeschwächte Erregung genügen, um $B C$ zur Kontraktion zu bringen. Was aber geschieht mit $A B$ ? Wir müssen doch a priori annehmen, dass der Reiz vor wie nach auch auf diese Strecke wirkt; wird derart schliesslich der ganze Fuss in Kontraktion verfallen?

Mir scheint, hier sind zwei Möglichkeiten vorhanden.

1. Massgebend für die Erregbarkeit des Muskels für einen (normalen) Nervenreiz bestimmter Intensität ist lediglich der Verkürzungsgrad des Muskels selbst, also etwa der mehr oder weniger grosse innere Widerstand, dergestalt jedenfalls, dass jeder Kontraktionshöhe eine bestimmte Erregungsintensität entspricht.

2. Massgebend für die Erregbarkeit sind Zustände innerhalb des Nervensystems, welche demnach die Erregung während ihrer Leitung beeinflussen, ihrerseits aber durch diese nicht, oder doch nicht unmittelbar, verändert werden.

Wie dies zu verstehen sei, wird aus dem Folgenden erhellen.

1. Unser Vorgang im Schneckenmuskel läuft also nach Annahme 1 folgendermassen ab: $A B$ kontrahiert sich unter dem Einflusse der (anatomisch) unmittelbareren Erregung, während der durch Leitung abgeschwächte Reiz die Strecke $B C$ nicht zu alterieren vermag. Durch die Kontraktion $A B$ wird Blut in $B C$ gepresst und diese Strecke gedehnt, so dass nunmehr auch sie sich kontrabieren kann, Sobald jedoch der Zustand erreicht ist, bei welchem sie zu Beginn unerregbar war, muss sie auch jetzt ihre Bewegung inhibieren. Bei gleichbleibendem Reize wird derart - vielleicht nach einigem Hinund Herschwanken - eine dauernde Kontraktion die Folge sein, die am stärksten bei $A$, am schwächsten bei $C$ sein würde. Bestätigt sich diese Annahme, so können wir unser Gesetz zur Erklärung der Lokomotion nicht gebrauchen, sondern wir müssen etwa einen komplizierten Reflexmechanismus für sie verantwortlich machen.

2. Nach Annahme 2 würde hingegen trotz erreichter Ausoangslänge bei $B C$ die Erregbarkeit immer noch grösser sein, da die Schwelle ja durch die Kontraktion unmittelbar gar nicht verändert wird.

Wenn uns also der experimentelle Nachweis gelingt, dass bei gleichem Reize, auch nach Erreichung des gleichen Verkürzungs- 
und daher Belastungszustandes zweier Muskeln, der ursprünglich tonusärmere die grössere Arbeit leistet, dann und nur dann haben wir die Erklärung erbracht, warum $B C$ sich nach Dehnung über seine ursprüngliche Länge hinaus kontrahieren und dadurch $A B$ oder eine andere Strecke ausdehnen kann, so dass nun Spiel auf Gegenspiel folgt.

$O b$ das "refraktäre Stadium" der Strecke $A B$ ausschliesslich in einer positiven Eigenschaft von $B C$ oder auch nebenbei noch in einer negativen Eigenschaft von $A B$ selbst zu suchen sei, dies zu entscheiden, sei vorläufig unsere Aufgabe nicht.

Ich glaube, die Fragestellung für das Experiment ist klar: Erst haben wir zu zeigen, dass überhaupt die Erregbarkeit eines Muskels um so höher ist, je geringeren Tonus er aufweist; ferner aber, dass bei gleichem Reize und versehiedenem Tonus der tonusärmere Muskel die grössere Arbeit leistet, auch von dem Punkte an gerechnet, an welchem Länge und Belastung für beide Muskeln die gleichen sind.

\section{Technik.}

Zum Messen der Ausschläge nach Reizungen habe ich den nämlichen Apparat verwandt wie zu den Versuchen über den Tonus, einen Apparat, bezüglich dessen Bau und Leistungen ich auf Mitteilung I verweisen muss. Wir messen also auf einer Briefwage die Last, die der Muskel bei einer bestimmten Länge zu tragen vermag, und die dem Drucke entspricht, den bei der nämlichen Länge der Muskel innerhalb des Tieres zu erzeugen in der Lage wäre. Im Prinzip handelt es sich also um einen, gegen eine Feder arbeitenden Muskel (Feder- oder Gewichtswage wäre ja ganz das nämliche), allein mit dem fundamentalen Unterschiede - verglichen mit dem quergestreiften Wirbeltiermuskel -, dass wir keinen Nullpunkt besitzen. Und zwar bezieht sich dies sowohl auf einen absoluten Nullpunkt (Tonus $=0$ ) als auf irgendeinen relativen. Demnach ist es weder durch isotonisches noch durch isometrisches Verfahren möglich, absolute Werte zu erhalten.

Wir gewinnen aber an unserem Apparate - da Länge und Belastung sich in einem bestimmten Verhältnisse zueinander verändern - Vergleichswerte, solange wir nämlich unter gleichen Bedingungen vergleichen, vor allem also für alle Vergleichsfälle dieselbe Ausgangsbelastung wählen.

Es wäre natürlich von Vorteil gewesen, jeweilig die ganze Kurve 
graphisch zu registrieren, allein über eine entsprechende myographionartige Vorrichtung verfüge ich nicht, und die ablesbaren Punkte der Kurven genügen uns in der Regel vollständig. Dafür hatte ich den Vorteil, das Verhalten des Tieres an meinem Apparate schon genau zu kennen.

Gereizt wurde im wesentlichen auf zwei Weisen: Entweder wurden Ganglien oder Bahnen (Nerven) direkt durch zwei Platinspitzen gereizt. Dabei waren die Platinspitzen auf dem verschiebbaren Ständer auf der Seite der Glasplatte fesst montiert. Oder aber das Tier lag auf zwei Stanniolblättchen, die auf dem Glase festgeklebt waren und mit je einem Pole des Induktionsapparates in Verbindung standen. Durch Grösse der Stanniolblätter und deren geringen Abstand (2,5 mm) war dafür gesorgt, dass in allen Fällen die vom Strom durchflossene Partie des Fusses möglichst gleich gross war. Ich will der Kürze halber von "direkter. Reizung“" (Bahnen und Ganglien) und "direkter Erregbarkeit" einerseits reden, andrerseits aber von "Reflexerregbarkeit" (Reizung des ganzen Fusses).

Wechselströme habe ich nur zur Bestimmung der Erregbarkeit. (= grösstmöglicher Rollenabstand) benutzt. Dabei war Sorge getragen, dass nur in unmittelbarer Folge erhaltene Zahlen verglichen wurden, dass die Stellschraube am Neef'schen Hammer durch eine zweite Schraube festgestellt war; dass ferner durch (sowieso notwendige) Pausen zwisehen den einzelnen Ablesungen die Polarisation in den Elementen nach Möglichkeit reduziert wurde.

Wenn es sich darum handelt, die Ausschlagshöhe festzustellen, tut man besser, Einzelschläge zu verwenden. Denn die an sich nie exakt dosierbare Dauer der Einwirkung von Wechselströmen ist nicht ohne Bedeutung für die zu messende Ausschlagshöhe; auch erbält man in der Regel keine einheitliche Reaktion. Nur bei Verwertung von minimalen Intensitäten gewinnt man bei Wechselströmen brauchbare Werte; doch sind diese minimalen Intensitäten wiederum nicht zu verwenden, wenn es gilt, mit ein und demselben Strome unter sehr verschiedenen Bedingungen überhaupt Reaktion zu erzielen.

Ich bin bei Feststellung der Ausschlagshöhe stets so verfahren: Der primäre Stromkreis ist (ausser durch den Neef'schen Hammer) durch einen Ausschalter unterbrechbar: einen Messinghebel, der auf einen halbkugligen Messingknopf gedrückt wird. So kann ich einen Schluss erzielen, bei dem langsames Ansteigen der Stromintensität 
vermieden wird. Benutzt wurde nur der Schliessungsschlag, da, bei meiner Vorrichtung, dieser mir aus mancherlei Gründen das gleichförmigste Resultat zu geben scheint. Der Öffnungsschlag wurde durch einen in den Sekundärkreislauf eingeschalteten Kurzschluss („Tetanisierschlüssel") abgeblendet.

Alle weiteren Einzelheiten sind bei den Versuchsprotokollen beschrieben. Die Versuche beziehen sich vorab nur auf Tiere ohne Ganglien oder doch ohne Cerebralganglion (Ausnahmen sind angegeben.) Sie wurden jeweilig mindestens dreimal wiederholt; doch teile ich, um die Arbeit nicht übermässig unfangreich zu gestalten, in der Regel nur ein Protokoll mit.

\section{Erregbarkeit und Dehnungszustand.}

Ein ganglienloser Muskel wird mit $7 \mathrm{~g}$ belastet und die mit Faden zusammengebundenen Bahnen auf die Platinstifte gelegt. Wechselstrom. Der Rollenabstand bezieht sich auf den Abstand des äusseren Randes der Primär- vom inneren Rande der Sekundärrolle, so also, dass beide gar nicht übereinandergreifen. Der Zeiger sinkt auf $2,2 \mathrm{~g}$.

In den Tabellen wird stets die Belastungszahl vor jeweiligem Stromschluss sowie diejenige Zahl angegeben, die der Zeiger als Kurvenmaximum erreicht. Die erste Zahlenrubrik soll stets mit "Einstellung", die letztere mit "nach Schluss" bezeichnet werden.

Tabelle 1.

Ganglienloses Tier, mit $7 \mathrm{~g}$ belastet.

\begin{tabular}{c|c|c}
\hline R.A. & Einstellung & nach Schluss \\
\hline 2 & 2,2 & 2,5 \\
2,25 & 2,2 & $\left.2,2^{1}\right)$
\end{tabular}

Die Kurbel wird angezogen, so dass nunmehr die Wage $20 \mathrm{~g}$ anzeigt. Der Muskel entlastet sich auf $12 \mathrm{~g}$.

1) Die Bestimmung der Erregbarkeit verlangt natürlich längeres Tasten. Ich begnüge mich, die letzte Zahl, bei der Erregbarkeit nachzuweisen war, sowie die erste Zahl anzugeben, bei der dies nicht mehr der Fall ist. Natürlich muss diese Grenze für jedes Tier aufs neue bestimmt werden, da sie grossen individuellen Schwankungen unterliegt. 
Untersuchungen zur Physiologie des Nervensystems bei Pulmonaten. II. 541

\begin{tabular}{c|c|c}
\hline R.-A. & Einstellung & nach Schluss \\
\hline 2,25 & 12 & 15 \\
3,0 & 12,5 & 13
\end{tabular}

Ganz die entsprechenden Resultate erhält man mit „normalen" und solchen Tieren, denen nur das Cerebralganglion fehlt.

Tabelle 2.

Normales Tier, mit $7 \mathrm{~g}$ belastet.

\begin{tabular}{c|c|c}
\hline R.-A. & Einstellung & nach Schluss \\
\hline 1 & 4,7 & 5,3 \\
1,25 & 4,3 & 4,3
\end{tabular}

Der Muskel wird mit $20 \mathrm{~g}$ belastet.

\begin{tabular}{l|l|r}
2 & 9 & 12,8 \\
2,5 & 9,5 & 9,8
\end{tabular}

Diesem Tiere wird das Cerebralganglion exstirpiert, und es wird auf $2,5 \mathrm{~g}$ entlastet.

\begin{tabular}{c|c|c}
\hline R.-A. & Einstellung & nach Schluss \\
\hline 2,0 & 2,9 & 4 \\
2,25 & 4,1 & 4,1 \\
\multicolumn{3}{|c|}{ Mit $20 \mathrm{~g}$ belastet } \\
2,5 & 11,5 & 16 \\
3,0 & 11,5 & 12,3
\end{tabular}

Die äusserste Grenze der Erregbarkeit nach „Hochbelastung" zu bestimmen, hatte natürlich keinen Zweck.

Diese Versuche berechtigen uns zu folgendem Schlusse:

Der durch Belastung gedehnte Muskel, der, wie wir in Mitteilung I sahen, durch diese Dehnung an Tonus eingebüsst hat, ist durch geringere Ströme, also leichter erregbar, als der minder belastete, daher minder gedehnte und tonusreichere Muskel. Mehr nicht. Die inneren Zustände der Muskeln unter den beiden gegensätzlichen Bedingungen können wir in keiner Weise bestimmen, daher wir denn auch nichts über die Arbeitsleistung in ihrem Verhältnis zum inneren Zustande aussagen können. Denn der innere Zustand des Muskels drückt sich aus in Länge und Belastung. Da aber ein bestimmtes Verhältnis dieser beiden Grössen zur Höhe des Tonus uns nicht bekannt ist, so erhalten wir eine Gleichung mit zwei nicht eliminierbaren Unbekannten. 
2. Tonus und Arbeitsleistung, berechnet rom gemeinsamen Nullpunkte gleicher Länge und gleicher Belastung.

Um den Muskel unter verschiedenen Bedingungen beobachten zu können, so dass wir Reaktionen erhalten, die quantitativ miteinander vergleichbar sind, dürfen wir die Lagebeziehung von Schnecke zu Wage also nicht verändern; auch müssen wir Sorge tragen, dass die Ausgangspunkte der Reaktion schon von vornherein möglichst dicht beieinanderliegen. Das klingt paradox: Der Muskel. soll ja in einem Falle geringeren Tonus aufweisen als im anderen. Und doch lässt sich der Bedingung in praxi mit genügender Exaktheit entsprechen. Ich will an einem fingierten Beispiele zeigen, wie wichtig die gestellte Bedingung ist, wenn es sich eben darum handelt, die Arbeitsleistungen der Muskeln zu bestimmen. Nehmen wir an, der Muskel stellt sich auf $12 \mathrm{~g}$ ein. Wir reizen mit Einzelschlag: der Zeiger steigt bis $13 \mathrm{~g}$. Nun vermindern wir in irgendeiner Weise den Tonus, so dass der Muskel sich auf $5 \mathrm{~g}$ einstellt. Ein neuer Einzelschlag bedingt Steigen auf 8 g. Es leuchtet ein, dass dieser Versuch gar nichts beweisen würde, da er wiederum inkommensurable Werte lieferte. Wenn aber in einem Falle der Ausschlag 5-6 beträgt, in einem zweiten Falle aber 5 (oder etwa 4,5 ) bis 7 , so würde unsere These zweifellos bewiesen sein.

Nun zeigt sich aber eine grosse Schwierigkeit. Wir kennen nur e in Mittel, von dem wir mit Bestimmtheit annehmen dürfen, dass es den Muskel nicht anders, als durch Tonusverminderung beeinflusst; das ist Belastung, und die dürfen wir unmittelbar nicht anwenden. Wärme, Alkaloide usw. geben keinerlei Garantie, dass sie ausschliesslich tonusmindernd wirken. Ich habe vorab mein Ziel dadurch erreichen wollen, dass ich zeigte, dass allen diesen Agentien der Erregbarkeit gegenüber die gleiche Wirkung zukäme. Später habe ich auf anderem Wege einwandfreie Resultate erhalten. Ich will aber doch die wichtigsten Versuche der ersten Art mitteilen, weil sie einmal die These bestätigen, dann aber an sich nicht obne Bedeutung zu sein scheinen.

a) Lässt man einen Schneckenmuskel nach beliebiger Belastung sich einstellen, und reizt man ihn dann mit starken Wechselströmen, so kann man, nach Ablauf der Kontraktion, an der neuen Einstellung nachweisen, dass der Muskel an Tonus verloren hat. (Gewisse Ausnahmen von dieser Regel haben für uns hier keine Bedeutung.) Diese Tatsache scheint mit dem von P. Schultz angegebenen Ver- 
halten glatter Wirbeltiermuskeln übereinzustimmen, dass nämlich der Tonus nicht bloss durch Belastung verringert wird, die den ruhenden Muskel trifft, sondern auch durch den Widerstand, den der sich kontrahierende Muskel zu überwinden hat.

Auf Grund dieses Befundes bin ich, wie folgt, verfahren:

\section{Tabelle 3.}

Cerebralloses Tier wird mit $25 \mathrm{~g}$ belastet. Es stellt sich auf $6,9 \mathrm{~g}$ ein. „Reflexerregung". (Die Rollen überdecken sich hierbei etwa zu $1 / 3$.)

EinzelschIag.

\begin{tabular}{c|c}
\hline Einstellung & nach Schluss \\
\hline 6,9 & 11,9
\end{tabular}

Nun lässt man Wechselstrom einwirken, bis der Zeiger $30 \mathrm{~g}$ anzeigt, unterbricht und wartet, bis der Zeiger den vorherigen Nullpunkt erreicht hat, um nunmehr wieder einen Einzelschlag wirken $\mathrm{zu}$ lassen, mit folgendem Resultat:

\begin{tabular}{c|c|c}
\hline & Einstellung & nach Schluss \\
\hline & 6,9 & 14,5 \\
$1,1)$ & 6,5 & 12 \\
& Wechselstrom bis $30 \mathrm{~g}$ \\
& 6,9 & 16 \\
1, & 7 & 12,7
\end{tabular}

Dieser Versuch beweist also, dass ein Muskel (dem in diesem Falle das Cerebralganglion fehlt) eine wesentlich grössere Arbeit, vom gleichen Nullpunkte an gerechnet, leistet, wenn er unmittelbar vorher durch energische Reizung zu starker Kontraktion (und Belastung) gebracht worden war, als vor diesem Eingriff. Da wir uns nicht denken können, dass energische Reizung an sich die Erregbarkeit steigern kann, so müssen wir annehmen, dass wir die erzielte heftige Reaktion der Tonusabnahme zuzuschreiben haben. Charakteristisch ist das einmalige Auftreten der erhöhten Kontraktion.

Den gleichen Nullpunkt erhalten wir hier dadurch, dass wir den Muskel bei seiner Wiederausdehnung an der gewünschten Stelle sozusagen abfangen.

1) Die Zeitangaben links von einer Rubrik solten stets die Pause bedeuten, nach der man den neuen Schlag hat einwirken lassen. 
Beim "normaleri" Tiere können wir die gleiche Erscheinung heobachten.

Tabelle $4 \mathrm{a}$.

Normales Tier, $10 \mathrm{~g}$, "Reflexerregung".

Einzelschlag.

\begin{tabular}{c|c}
\hline Einstellung & nach Schluss \\
\hline 4,5 & 14,2 \\
Durch Wechselstrom auf $28 \mathrm{~g}$ \\
4,9 & 17,0
\end{tabular}

Ferner kann man auch in dieser Weise die „direkte" Erregbarkeit prüfen, mit gleichem Resultate:

Tabelle $4 \mathrm{~b}$.

Normales Tier; Elektroden unter den Hauptbahnen. Ausnahmsweise Doppelschläge. (Der Ausschalter wird schnell über den Messingknopf hinweggedrückt.)

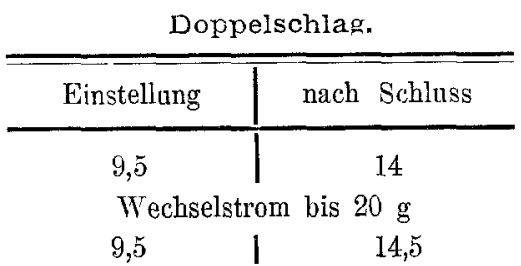

(Versuch nicht wiederholt.)

Nicht ganz eindeutig sind die Resultate für das ganglienlose Tier, weil, wie sich zeigt, zwei Erscheinungen durcheinanderlaufen.

Tabelle 5.

Ganglienloses Tier, $7 \mathrm{~g}$, Reflexerregung.

Einzelschläge.

\begin{tabular}{c|c|c}
\hline Pause & Einstellung & nach Schluss \\
\hline & 4,9 & 8,2 \\
$9 \prime$ & 5,2 & 7,3 \\
5, & 5,1 & 7,6 \\
\multicolumn{2}{|c|}{ Durch We echselstrom auf $15 \mathrm{~g}$} \\
$16^{1 / 2}$, & 6,1 (Minimum!) & 9 \\
& 6,1 & 7,9 \\
& 6,0 & 7,3
\end{tabular}

Hier ist von einer Tonusabnahme gar keine Rede; es ist mir auch nicht möglich zu beweisen, dass der erste erhöhte Ausschlag nicht der langen vorhergehenden Pause zuzuschreiben ist, die beim 
ganglienlosen Tier ziemlich viel Berleutung hat. Ich will hier schon auf die Tatsache der "Tonusladung" durch künstliche Reize beim ganglienlosen Tiere hinweisen (vgl. auch Mitteilung I: Tonuszunahme nach Entfernung der Ganglien). Wenn es mir auch noch nicht möglich ist, Bestimmtes mitzuteilen, so glaube ich doch jetzt schon sagen zu können, dass dieser Begriff „Tonusladung" auf künstlichen Reiz hin, uns in einer künftigen Mitteilung wird zu beschäftigen haben. Unter gewissen Bedingungen ist die Erscheinung konstant; dann vor allem, wenn der bei der Kontraktion zu überwindende Widerstand nicht zu gross ist. Bei obigem Versuche haben wir es also mit zwei entgegengesetzten Einwirkungen auf den Muskel zut tun. Vornehmlich um auf diese Verhältnisse hinzuweisen, habe ich den Versuch mitgeteilt.

b) Dass Wärme den Tonus herabzusetzen vermag, ist bekannt. Ich habe folgendes Verfahren benutzt, um Wärme auf den Schneckenmuskel wirken zu lassen, der am Apparate arbeitet: Ich habe mir aus Messingblech einen viereckigen Kasten zusammengelötet, der etwa $6 \mathrm{~cm}$ lang, $4 \mathrm{~cm}$ hoch und $3 \mathrm{~cm}$ breit ist. Die beiden schmalen Seitenwände tragen nahe am Boden je ein kreisrundes Loch von 2,5 cm Durchmesser, in das eine Blechröhre gleichen Durchmessers eingelötet sich befindet, die ebenso lang ist als der Kasten. Bringe ich diese Vorrichtung zwischen Wage und Kurbel, so kann eine in dem Blechrohr liegende Schnecke am Apparate arbeiten, während ich in die Wanne Wasser von beliebiger Temperatur bringen kann, von dem das Tier dann völlig umspült ist, ohne mit dem Wasser selbst in Berührung zu kommen. Reflexerregung wird erzielt durch Übertragung des einen Pols auf den Blechkasten, des anderen aber unmittelbar auf die Sehnecke, und zwar durch einen Stanniolstreifen. (Auch der Blechzylinder ist innerlich verzinnt.)

Tabelle 6.

Helix ohne Cerebralganglion, $7 \mathrm{~g}$; im "Wärmekasten" Reflexerregung.

\begin{tabular}{|c|c|c|c|}
\hline Wassertemperatur & Zeit & Einstellung & nach Schluss \\
\hline $9,5-11,2^{0}$ & $\begin{array}{l}12 \text { h } 24^{\prime} \\
12 \text { h } 26^{\prime} \\
12 \text { h } 28^{\prime}\end{array}$ & $\begin{array}{l}1,5 \\
1,5 \\
2,2\end{array}$ & $\begin{array}{l}2 \text { langsam } \\
2,3 \quad " \\
2,6 " ~\end{array}$ \\
\hline $37-33,8^{\circ}$ & $\begin{array}{l}12 \text { h } 42^{\prime} \\
12 \text { h } 44^{\prime} \\
12 \text { h } 46^{\prime} \\
12 \text { h } 48^{\prime}\end{array}$ & $\begin{array}{l}1,5 \\
1,4 \\
1,3 \\
1,2\end{array}$ & $\begin{array}{lc}3 & \text { schnell } \\
2,9 & " \\
2,7 & " \\
2,8 & "\end{array}$ \\
\hline
\end{tabular}




\begin{tabular}{|c|c|c|c|}
\hline Wassertemperatur & Zeit & Einstellung & nach Schluss \\
\hline $9-11^{0}$ & $\begin{array}{l}1 \text { h h } \\
1 \text { h h } 2^{\prime} \\
1 \text { h } 4^{\prime}\end{array}$ & $\begin{array}{l}1,8 \\
1,9 \\
1,8\end{array}$ & $\begin{array}{l}2,3 \text { langsam } \\
2,1 \quad " \\
2,1 \quad "\end{array}$ \\
\hline
\end{tabular}

Ganz die nämlichen Resultate erbält man beim ganglienlosen Tiere, z. B.:

Tabelle 7 .

Ganglienloses Tier, $7 \mathrm{~g}$; im "Wärmekasten" Reflexerregung.

\begin{tabular}{c|c|c|c}
\hline $\begin{array}{c}\text { Temperatur } \\
\text { des Wassers }\end{array}$ & Einstellung & nach Schluss & \\
\hline $12^{\circ}$ & 1,6 & 2,2 & $\begin{array}{c}\text { sehr langsam } \\
\text { sehr schnell }\end{array}$
\end{tabular}

usw. mit stets analogen Werten.

Es ist uns also gelungen, durch Anwendung sehr geringer Belastung die tonische Reaktion (Fall in der Wärme, Steigerung in der Kälte) so zu verkleinern, dass wir durchaus kommensurable Grössen erzielt haben: Die vom erwärmten Muskel geleistete Arbeit unter gleichen Bedingungen und vom gleichen Nullpunkte aus ist grösser als die vom gekühlten Muskel. Es ist nicht ausgeschlossen, dass auch hier die Wirkung der Wärme auf den Tonus, für die Reaktion verantwortlich zu machen ist.

c) Den Muskel selbst zu kokainisieren, geht nicht an, da wir das Leitvermögen des Reflexbogens zu sehr beeinträchtigen würden. Hingegen habe ich schon früher gezeigt, dass nach Kokainisierung der Pedalganglien der Tonus fällt. Mit dieser Methode erzielt man die nämlichen Resultate als mit den vorigen. Doch will ich die letztern erst mitteilen, wenn, wir dazu übergehen, die regulative Funktion der Ganglien zu besprechen.

d) Hauptrersuche: Ich habe schon gesagt, dass alle diese Versuche nicht einwandfrei sind: Wärme oder Applikation von Kokain auf das Pedalganglion könnten die gesteigerte Erregbarkeit in ganz anderer Weise bedingen. Ob aber bei Anwendung starker Reizung wirklich der überwundene Widerstand die Erregbarkeit dureh Herabsetzung des Tonus steigert, und nicht etwa die Elektrisierung irgendeinen uns unbekannten Einfluss hat - ja, beweisen können wir das auch nicht. 
Nun habe ich in der I. Mitteilung gezeigt, dass wir ein Tier in der Medianebene (der Länge nach) derart in zwei Hälften zerlegen können, dass diese nur mehr durch dass Nervensystem kommunizieren. Belaste ich nun die eine Hälfte, so sinkt auch der Tonus in der anderen. Hier also haben wir ein Mittel, den Tonus lediglich durch Belastung zu beeinflussen und doch am Verhältnis zwischen Muskel und Wage nichts zu ändern. Aber es sind noch mehr Gründe vorhanden, denen zufolge diese Versuchsanordnung besonders interessante Resultate zu geben berufen erscheint: Wenn wir den registrierenden Teil niedrig belasten, so dokumentiert sich der Tonusfall nach Belastung der anderen Hälfte fast gar nicht. (Vgl. Mitteilung I.) Das Agens ist das nämliche; ein wenig gedehnter Muskel wird sich eher leichter ausdehnen lassen als ein solcher, auf den hohe Belastung gewirkt hat; die Belastung ist endlich noch reichlich hoch genug, um den Tonusfall anzuzeigen. Wenn ein solcher im Muskel nicht nachzuweisen ist, so muss dies, wie schon in Mitteilung I gesagt, am leitenden Apparate liegen. Wenn es uns also hier gelingt, bei gleichem Zustande des registrierenden Muskels höheren Anschlag zu erzielen, sobald die andere Tierhälfte belastet ist, dann können wir mit grosser Bestimmtheit sagen: Die Erregbarkeit ist abbängig von einem aktiven Zustande des Nervensystems, und damit (in den meisten Fällen wenigstens) auch des Muskels. Ausschlaggebend aber ist der Zustand des Nervensystems.

Tabelle 8.

Helix ohne Cerebralganglion. "Halbtierversuch". Reflexerregung (durch Einzelschläge) der registrierenden Hälfte.

\begin{tabular}{|c|c|c|c|}
\hline \multirow{2}{*}{$\begin{array}{c}\text { Belasteter Teil } \\
\text { trägt }\end{array}$} & \multirow{2}{*}{ Zeit } & \multicolumn{2}{|c|}{ Registrierende Hälfte } \\
\hline & & Einstellung & nach Schluss \\
\hline $0 \mathrm{~g}$ & $\begin{array}{l}11 \mathrm{~h} \tilde{o}^{\prime} \\
11 \mathrm{~h}\end{array}$ & $\begin{array}{l}0,9 \\
0,9\end{array}$ & $\begin{array}{l}1,2 \\
1,2\end{array}$ \\
\hline $20 \mathrm{~g}$ & $\begin{array}{l}11 \text { h } 9^{\prime} \\
11 \text { h } 11^{\prime}\end{array}$ & $\begin{array}{l}1 \\
1\end{array}$ & $\begin{array}{l}1,8 \\
1,8\end{array}$ \\
\hline
\end{tabular}

Noch besser ist das in Tab. 9 (S. 548) folgende Beispiel unter gleichen Bedingungen.

Natürlich fallen die Werte weit mehr ins Auge, wenn man den registrierenden Teil höher belastet, wenn dann auch ein gleicher Nullpunkt gar nicht oder doch nur mit Kunstgriffen zu erreichen ist. Auf einen solchen Kunstgriff deutet der Vermerk "abgefangen" 
hin, d. h. hier ist die Pause von drei Minuten nicht abgewartet, sondern unmittelbar gereizt worden, als der Zeiger den gewünschten Punkt anzeigte.

\section{Tabelle 9.}

Gleiche Bedingungen wie in Tabelle 8.

\begin{tabular}{|c|c|c|c|}
\hline \multirow{2}{*}{$\begin{array}{l}\text { Belasteter Teil } \\
\text { trägt }\end{array}$} & \multirow{2}{*}{ Zeit } & \multicolumn{2}{|c|}{ Registrierende Hälfte } \\
\hline & & Einstellung & nach Schluss \\
\hline $0 \mathrm{~g}$ & $\begin{array}{l}10 \mathrm{~h} 37^{\prime} \\
10 \mathrm{~h} 39^{\prime} \\
10 \mathrm{~h} 41^{\prime}\end{array}$ & $\begin{array}{l}2,2 \\
\mathbf{2}, 3 \\
2,2\end{array}$ & $\begin{array}{l}3,9 \\
4 \\
3,9\end{array}$ \\
\hline $20 \mathrm{~g}$ & $\begin{array}{l}10 \text { h } 43 \\
10 \text { h } 45^{\prime}\end{array}$ & $\begin{array}{l}\mathbf{2}, 4 \\
1,5\end{array}$ & $\begin{array}{l}4,9 \\
3,2\end{array}$ \\
\hline $0 \mathrm{~g}$ & $\begin{array}{l}10 \text { h } 48^{\prime} \\
10 \text { h } 50^{\prime}\end{array}$ & $\begin{array}{l}2,5 \\
3,4\end{array}$ & $\begin{array}{l}3,9 \\
4,7\end{array}$ \\
\hline
\end{tabular}

Tabelle 10.

Helix ohne Cerebral. Belastung der registrierenden Hälfte: $15 \mathrm{~g}$. Reflexerregung der registrierenden Hälfte (Einzelschläge).

\begin{tabular}{|c|c|c|c|}
\hline \multirow{2}{*}{$\begin{array}{l}\text { Belastete Hälfte } \\
\text { trägt }\end{array}$} & \multirow{2}{*}{ Pause } & \multicolumn{2}{|c|}{ Registrierende Hälfte } \\
\hline & & Einstellung & nach Schluss \\
\hline $30 \mathrm{~g}$ & & 7 & 10,3 \\
\hline $0 \mathrm{~g}$ & $\begin{array}{l}3 \prime \\
3^{\prime}\end{array}$ & $\begin{array}{l}9,1 \\
7,9\end{array}$ & $\begin{array}{c}10,2 \\
8\end{array}$ \\
\hline
\end{tabular}

Tabelle ll.

Gleiche Bedingungen wie in Tabelle 10.

\begin{tabular}{|c|c|c|c|c|}
\hline \multirow{2}{*}{$\begin{array}{c}\text { Belastete Hälfte } \\
\text { trägt }\end{array}$} & \multirow{2}{*}{ Pause } & \multicolumn{2}{|c|}{ Registrierende Hälfte } & \\
\hline & & Einstellung & nach Schluss & \\
\hline $0 \mathrm{~g}$ & $3^{\prime}$ & $\begin{array}{c}10,0 \\
9\end{array}$ & $\begin{array}{r}10,1 \\
9,8\end{array}$ & \\
\hline $30 \mathrm{~g}$ & $\begin{array}{l}33^{\prime} \\
3^{\prime} \\
3^{\prime}\end{array}$ & $\begin{array}{c}9 \\
10,0 \\
10,0\end{array}$ & $\begin{array}{l}10,3 \\
11,1 \\
12,3\end{array}$ & $\begin{array}{c}\text { abgefangen } \\
n \\
"\end{array}$ \\
\hline $0 \mathrm{~g}$ & $3^{\prime}$ & 10,1 & 10,6 & lange Latenz \\
\hline
\end{tabular}

Der Tonus steigt immer mehr (Minimum $12 \mathrm{~g}$ ), so dass Resultate nicht mehr zu erhalten sind.

Ihrer Wichtigkeit halber wurden diese Versuche besonders oft ausgeführt; ich will aber noch das Folgende hierzu be- 
merken: Ich würde mich nicht gern entschliessen, derartige "Halbtierversuche" etwa in einer Vorlesung zu demonstrieren, da sie überaus delikat sind. Wenn nicht schon auf leise Berührung der einen Seite energische Kontraktion der anderen folgt, so soll man das Präparat nicht benutzen. Ich habe manchen Tag vier bis fünf Tiere operiert, ohne dass ich ein brauchbares Präparat erzielt hätte. Immerhin ist es mir für diese Verzuchsreihe siebenmal ganz einwandfrei gelungen, und dann habe ich unter obigen Bedingungen stets das angegebene Resultat erhalten.

$\mathrm{Zu}$ welcher Behauptung berechtigen uns nun diese Resultate? Man wird unschwer erkennen, dass sie über die Tonusfrage wichtige Aufschlüsse zu geben imstande sind. Allein damit werden wir uns erst im Abschnitt III zu beschäftigen haben.

Es ist aber bewiesen worden, dass ein Muskel, der verminderten Tonus aufweist, oder aber, dermitnervösen Elementen in Verbindung steht, deren Zustand einem verminderten Tonus entspricht, ohne dass sich diese Verminderung im Muskel selbst dokumentieren müsste, dass, sage ich, ein solcher Muskel mehr Arbeit leistet als ein Maskel ohne jene Verminderung. Diese Arbeitsleistung ist unabüngig von einem inneren Zustande des Muskels, da wir sie (die Arbeitsleistung) eben vom gleichen Nullpunkte aus berechnet haben, (gleiche Länge der verglichenen Muskeln bei gleicher Last).

Ich hebe besonders hervor, dass alle diese Versuche unter Bedingungen angestellt sind, die einem normalen Mechanismus nicht entsprechen. Damit will ich sagen: Wo eine besondere Anpassung vorliegt, da, aber nur da, werden wir die Möglichkeit zugeben, dass unser Eingriff (wenn er wenigstens den in der Natur gestellten Bedingungen entspricht) nicht unmittelbar, sondern durch Auslösung eines komplizierten, durch Anpassung entstandenen Mechanismus, die Reaktion hervorruft. Die Natur erreicht ihren $Z_{w e c k}$ stets, auch wenn sie sich nicht des Weges bedient, der uns am einfachşten erscheint. Ein bestimmtes Verhalten innerhalb der Z w e ckmässígkeit des Organismus bedarf der Erklärung, ausserhalb der Zweckmässigkejt gewährt es eine Erklärung: Fin komplizierter Reflexmechanismus, der bei der Schnecke die Lokomotion zuzuschreiben wäre, würde weder innerhalb des ganzen Muskels als Einheit in der dargetanen Weise Gültigkeit haben, noch 
würden Kontraktion und Dehnuıg durch unsere Eingriffe ersetzbar sein können. ${ }^{1}$ )

W.erfen wir nun noch einen Blick auf unser Lokomotionsschema: $A B$ kontrahiert sich und dehnt $B C$; dadureh wird $B C$ erregbarer, so dass diese Strecke sich nun zusammenzieht; aber mehr noch: $B C$ wird auch mehr Arbeit leisten als $A B$ sie geleistet hat, wird sich über seinen Ausgangszustand hinaus zusammenziehen und dadurch $A B$ ausdehnen. Kurz, Spiel und Wechselspiel. Doch bleiben für die Erklärung der Lokomotionsperistaltik drei Probleme:

1. Warum kontrahiert sich vorab $A B$ und nicht $B C$ ? Unsere anatomische Erklärungsweise beruhte auf einer Annahme.

2. Was bedingt die gleichmässige Richtung der Peristaltik von hinten nach vorn (Antiperistaltik).

3. Wie erfolgen auf die Dauer neben den Erregungsschwankungen die Tonussehwankungen; wird die zu postulierende Restitution des Tonus zur Norm (nach jeder Kontraktion) durch die Entlastung, oder durch "Tonusladung“ auf Erregung hin bedingt?

Diese drei. Fragen haben uns in einer nächsten Mitteilung zu beschäftigen. Auf eine definitive Synthese der Lokomotion kam mirs für diesmal nicht an: Wir haben uns vielmehr (gleichwie in der ersten Mitteilung) die Aufgabe gestellt, die Grundfunktionen der Schneckenmuskulatur, soweit ihre Kenntnis für unsere Zwecke notwendig zu sein schien, analytisch zu bestimmen und ihre Regulation durch die Ganglien zu studieren.

Da es nun sehr wahrscheinlich, ja leicht experimentell zu beweisen ist, dass Einflüsse, die die Erregbarkeit steigern, auch die Lokomotion beschleunigen, so haben wir uns vorab zu fragen, wie wird die Erregbarkeit durch die Ganglien reguliert?

1) Ich habe dies ausgeführt, weil Bied ermann (Pflüger's Arch. Bd. 102 S. 515 usw.) die "biologische Bedeutung“ gerade gewissen Erklärungsversuchen von v. U exküll entgegenbält. In der Tat, betrachten wir den oben beschriebenen Versuch am Seestern (von dem bei Biedermann übrigens nicht die Rede ist), so würde vielleicht die nämliche Reaktion erfolgen, wenn Dehnung oder Kontraktion einen entsprechenden antagonistischen Reflex auslösen würde, hier zu schwach, um allein zu wirken, durch "Reizsummation" aber herbeigeführt. Mir scheint der Einwand für dies Beispiel freilich etwas gekünstelt, doch nicht unzulässig. 


\section{B. Die Regnlierung der Erregbarkeit durch die Ganglien.}

\section{Das Pedalganglion.}

Meines Wissens ist $\mathrm{Loeb}^{\mathbf{1}}$ ) der erste gewesen, der die Bedeutung des Ganglion bei solchen Tieren untersucht hat, die nur über ein einziges solches Organ verfügen, nämlich bei den Ascidien (1. c. S. 22 ff.). Er fand, dass eine ibres Ganglion beraubte Ciona vor wie nach einen bestimmten Reflex auszuführen vermag, nur wird die Erregbarkeit eine geringere. $\mathrm{L} 0$ e $\mathrm{b}$ hat dieser Erscheinung die richtige Erklärung gegeben: Die Bahnen leiten besser als das periphere Netz. Ein solches können wir mit Bestimmtheit an Stelle leitender Muskeln setzen, von denen Loeb damals noch glaubte sprechen zu müssen, obwohl auch er schon darauf hinweist, dass möglicherweise noch ein peripheres Nervensystem vorhanden sei.

Dass die peripheren Netze der Schnecken wesentlich schlechter leiten als die Bahnen, hat Bethe ${ }^{2}$ ) direkt gezeigt (für Arion S. 119f.), und auch wir fanden bei "Halbtier".Tonusversuchen (Mitt. I) einen viel geringeren Ausgleich durch die Netze als durch die Bahnen.

Die von $L 0 e b$ für das dargetane Verhalten der Reflexerregbarkeit gegebene Erklärung, lässt sich mit Leichtigkeit für Helix als zu Recht bestehend nachweisen.

Tabelle 12.

Normale Helix mit $7 \mathrm{~g}$ belastet. Reflexerregung durch Einzelschläge.

\begin{tabular}{|c|c|}
\hline Einstellung & nach Schluss. \\
\hline $\begin{array}{l}4 \\
3\end{array}$ & $\begin{array}{l}6 \\
5,5\end{array}$ \\
\hline Exstirpati & r Ganglien \\
\hline 4 & 4,5 \\
\hline $\begin{array}{l}2,1 \\
2,1\end{array}$ & $\cdot \begin{array}{l}3 \\
2,7\end{array}$ \\
\hline
\end{tabular}

Genau wie bei Ciona bedingt bei Helix die Anwesenheit der Ganglien gesteigerte Reflexerregbarkeit. Der Versuch kann auch

1) J. Loeb, Einleitung in die vergleichende Gehirnphysiologie. J. A mbrosius Barth, Leipzig 1899. Enthält die Literatur. Ich zitiere nach dem Buche selbst.

2) Albrecht Bethe, Allgemeine Anatomie und Physiologie des Nervensystems. Georg Thieme, Leipzig 1903. 
mit Bestimmung der Reizschwelle angestellt werden, ohne dass das Resultat sich veränderte. Noch deutlicher würde das Resultat gewesen sein, würden wir das ganglienlose Tier mit demjenigen verglichen haben, dem das Cerebrale entfernt worden ist.

Bei diesem Versuche dürfen wir nicht stehen bleiben, wenn es uns einmal darum zu tun ist, nachzuweisen, dass obige Erscheinung wirklieh nur dem grösseren Leitungswiderstande zuzuschreiben ist, ferner aber, wenn wir uns die Frage vorlegen, ob denn das Pedalganglion gar keinen unmittel baren Einfluss auf die Erregbarkeit der Muskulatur hat. Es bleibt für uns die "direkte Erregbarkeit" mit und ohne Pedalganglion zu prüfen, da dergestalt die leitenden Bahnen stets die gleichen sind.

Die Technik ist folgende: Man öfnet das Tier, entfernt das Cerebralganglion und durchtrennt alle diejenigen Bahnen, die die Pedalganglien unmittelbar mit den zunächstliegenden Muskelpartien verbinden, die also nach Exstirpation der Pedalganglien, durch den Strom nicht mehr in Erregung versetzt werden würden. Dann legt man vorsichtig um den Rest der Bahnen eine Fadenseblinge, aber ganz lose, so dass sie durchaus keinen Druck auf die Bahnen ausübt. Diese Schlinge wird später, unmittelbar vor Entfernung der Ganglien zugezogen. Unterlässt man diesen Handgriff, so werden durch die Kontraktion - ihrerseits eine Folge des Eingriffs - die Nervenstumpfe häufig von den Platindrähten herabgezogen, und man hat zum mindesten keine Garantie dafür, dass man nach der Exstirpation die gleiche Anzahl von Bahnen der Reizung aussetzt als vorher. Man muss nicht vergessen, wie klein diese Gebilde, sowie die zur Verfügung stehenden Strecken der Bahnen sind. Schon bei Limax oder Arion wird dieser Versuch bequemer, allein es ist wichtig, alle Versuche an einem Objekte anzustellen, und im allgemeinen eignet sich Helix viel besser.

Tabelle 13.

Helix, in angegebener Weise präpariert, wird mit $10 \mathrm{~g}$ belastet. Der Rest der Bahnen befindet sich auf den Platinstiften. Wechselströme. Direkte Erregbarkeit.

\begin{tabular}{|c|c|c|c|}
\hline Pause & $\begin{array}{c}\text { R.-A. } \\
\mathrm{cm}\end{array}$ & Einstellung & nach Schluss \\
\hline je 1 Minute & $\begin{array}{l}2 \\
\mathbb{2}, 5 \\
3\end{array}$ & $\begin{array}{l}5 \\
5 \\
5\end{array}$ & $\begin{array}{l}5,3 \\
\mathbf{5}, 2 \\
5\end{array}$ \\
\hline
\end{tabular}


Untersuchungen zur Physiologie des Nervensystems bei Pulmonaten. II. 553

\begin{tabular}{l|c|c|c} 
Pause & $\begin{array}{c}\text { R.-A. } \\
\mathrm{cm}\end{array}$ & Einstellung & nach Schluss \\
\hline
\end{tabular}

Ohne Pedalganglien

je 1 Minute

\begin{tabular}{l|l|l}
3 & 7,2 & 7,2 \\
2,5 & 7,2 & 7,2 \\
2,0 & 6,9 & 7,1 \\
$\mathbf{2}, \mathbf{0}$ & $\mathbf{6 , 1}$ & $\mathbf{6 , 3}$
\end{tabular}

Zwei andere Beispiele. Gleiche Bedingungen.

Tabelle 14.

\begin{tabular}{|c|c|c|c|c|c|c|}
\hline \multirow{2}{*}{ Pause } & \multicolumn{3}{|c|}{ Tier 2.} & \multicolumn{3}{|c|}{ Tier 3.} \\
\hline & $\begin{array}{c}\text { R. }-A . \\
\mathrm{cm}\end{array}$ & $\begin{array}{c}\text { Ein- } \\
\text { stellung }\end{array}$ & $\begin{array}{c}\text { nach } \\
\text { Schluss }\end{array}$ & $\begin{array}{c}\text { R. }-A . \\
\mathrm{cm}\end{array}$ & $\begin{array}{c}\text { Ein- } \\
\text { stellung }\end{array}$ & $\begin{array}{l}\text { nach } \\
\text { Schluss }\end{array}$ \\
\hline $\begin{array}{l}\text { je } 1 \text { Min. für } \\
\text { beide Ver- } \\
\text { suchsreihen }\end{array}$ & $\begin{array}{l}2,5 \\
2,25\end{array}$ & $\begin{array}{l}4,3 \\
4,0\end{array}$ & $\begin{array}{l}4,3 \\
4,5\end{array}$ & $\begin{array}{l}3 \\
3,5\end{array}$ & $\begin{array}{l}5 \\
5\end{array}$ & $\begin{array}{l}6 \\
5\end{array}$ \\
\hline \multicolumn{7}{|c|}{ Ohne Pedalganglien } \\
\hline & $\begin{array}{l}2,25 \\
2,25 \\
2,5\end{array}$ & $\begin{array}{l}4,3 \\
4,0 \\
3,9\end{array}$ & $\begin{array}{l}4,6 \\
4,5 \\
3,9\end{array}$ & $\begin{array}{l}3,5 \\
3\end{array}$ & $\begin{array}{l}5 \\
5\end{array}$ & $\begin{array}{l}5 \\
6\end{array}$ \\
\hline
\end{tabular}

Diese Versuche sind im ganzen fünfmal mit entsprechenden Resultaten ausgeführt worden. Die beiden letzten Beispiele sind insofern besonders lehrreich, als es gelungen ist, eine Belastung zu wählen, die für diese Tiere bedingte, dass die Pedalexstirpation den Tonus nicht veränderte. Wie dies möglich sei, wird jeder, der Mitteilung I kennt, ohne weiteres verstehen.

In diesem Falle hat die Exstirpation der Pedalganglien auf die direkte Erregbarkeit gar keinen Einfluss.

Bei Tier Nr. 1 bedingt die Exstirpation Steigerung des Tonus, demzufolge auch herabgesetzte Erregbarkeit (allerdings nur in sehr bescheidenen Grenzen). Dass dieser Einfluss auf die Erregbarkeit lediglich ein mittelbarer ist, herbeigeführt durch die uns bekannten Veränderungen im Tonus, kann ich dadurch zeigen, dass nach Exstirpation der Pedalganglien auch Steigerung der Erregbarkeit eintreten kann, wenn nämlich die Exstirpation nur auch Tonusfall zur Folge hat ("Hochbelastung"). (Siehe Tab. 15 S. 554.)

Ich meine, diese Versuche geben uns ein volles Recht zu sagen: Die Pedalganglien regulieren die Erregbarkeit nur mittelbar, insofern namlich, alssieden Tonuszu regulieren vermögen, von diesem aber die Erregbarkeit abhängt. 
Tabelle 15.

Heljx mit $15 \mathrm{~g}$ belastet. Sonst gleiche Bedingungen wie in Tabelle 13 und 14.

\begin{tabular}{c|c|c}
\hline $\begin{array}{c}\text { R.-A. } \\
\mathrm{cm}\end{array}$ & Einstellung & nach Schluss \\
\hline 3 & 4,2 & $\begin{array}{c}\text { Erregbarkeit eben } \\
\text { nachzuweisen }\end{array}$
\end{tabular}

Ohne Pedalganglien.

\begin{tabular}{|c|c|}
\hline 3 & $\mathbf{3}, \mathbf{5}$ \\
\hline
\end{tabular}

Nach dem Gesagten dürfte es unschwer sein, vorauszusagen, wie diese Regulation je nach Zustand der Ganglien ausfallen wird. - Ich teile die entsprechenden Versuche mit, da ihre Resultate das Vorstehende einmal zu stützen vermögen, wir aber vor allen Dingen zu ihnen, weiter unten, interessante Parallelversuche werden dartun können.

In meiner Arbeit über Aplysia (S. 232) und neuerdings in Mitteilung I (S. 217) habe ich gezeigt, dass Kokainisierung der Pedalganglien Tonusfall bedingt. Wie wirkt nun dieser Eingriff auf die Erregbarkeit? Die Versuche, deren Resultat ich schon weiter oben verwertete, sind folgende:

Tabelle 16.

Helix ohne Cerebralganglion. Belastung $7 \mathrm{~g}$. Reflexerregung durch Einzelschläge.

\begin{tabular}{|c|c|c|}
\hline Zeit & Einstellung & nach Schluss \\
\hline $\begin{array}{l}11 \mathrm{~h} \\
11 \mathrm{~h} \\
11 \mathrm{~h}, \\
4^{\prime}\end{array}$ & $\begin{array}{l}1,5 \\
2 \\
1,8\end{array}$ & $\begin{array}{l}4,1 \\
4,1 \\
\mathbf{3}\end{array}$ \\
\hline
\end{tabular}

Kokain von $2,5{ }^{0}\left(0^{1}\right)$ wird vorsichtig auf die Pedalganglien aufgepinselt.

\begin{tabular}{l|l|l}
\hline $11^{\text {h }} 6$, & $\mathbf{1 , 8}$ & $\mathbf{0}, \mathbf{5} \quad$ (schneller Fall auf $\mathbf{1 , 2}$ )
\end{tabular}

Je mehr das Kokain eindringt, desto mehr nimmt das Tier den Habitus eines ganglienlosen Tieres an.

\begin{tabular}{l|l|l}
\hline $11 \mathrm{~h} 10^{\prime}$ & $\mathbf{2 , 2}$ & $\mathbf{3 , 5}$
\end{tabular}

1) Ich habe stets den Kokainlösungen Neutralrot zngesetzt, um feststellen zu können, ob sich das Alkaloid anch nicht innerhalb des Schneckenkörpers verbreite. 
Die Pedalganglien können zu dieser Zeit mit der Pinzette zerquetscht werden, ohne dass der Muskel reagiert. Exstirpation der Pedalganglien bedingt nunmehr natürlich keinerlei Änderung im Verhalten; (der Tonus nimmt so wie so zu).

Gleiches Tier ohne Pedalganglien.

\begin{tabular}{c|c|c}
\hline \hline Zeit & Einstellung & nach Schluss \\
\hline $11^{\mathrm{h}} 14^{\prime}$ & 3 & 4,1
\end{tabular}

Ich will hierbei eine Bemerkung über die Technik der Vergiftung von Ganglien durch Bepinselung machen. Sie gibt erst zuverlässige Resultate, wenn man über ausreichende Frfahrung über den Modus verfügt, wie das Alkaloid eindringt. Die hierzu erforderliche Zeit unterliegt nämlich beträchtlichen individuellen Schwankungen. Bei unserem ersten Versuch tritt schon zwei Minuten nach der Bepinselung die Reaktion auf. Sechs Minuten danach sind die Pedalganglien gelähmt. Diesem Versuche möchte ich die folgenden an: die Seite stellen.

Tabelle 17.

Gleiche Bedingungen wie in Tab. 16.

\begin{tabular}{c|c|c|c}
\hline \hline Zeit & Einstellung & nach Schluss & \\
\hline 10 h $27^{\prime}$ & 2,3 & 4,9 & \\
$10^{\mathrm{h}} 29^{\prime}$ & 4,3 & 5,1 & \\
$10^{\mathrm{h}} 31^{\prime}$ & 5,5 & 6,3 &
\end{tabular}

Kokain $2,5 \%$ auf die Pedalganglien

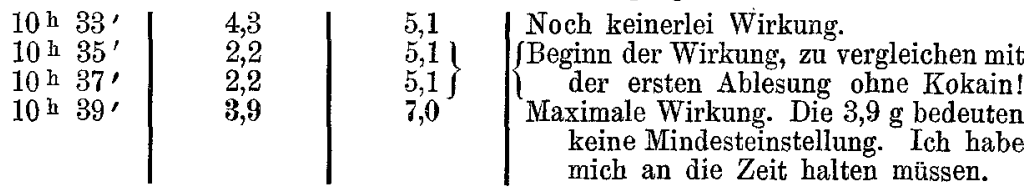

Nunmehr Exstirpation der Pedalganglien

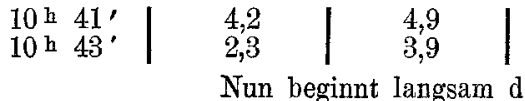

$10^{\text {h }} 45^{\prime}$ । 3,1 । 4,4 ।

Dieser Versuch zeigt, verglichen mit dem ersten, dass beträchtliche Zeitdifferenzen, wie oben dargetan, zwar nachweisbar sind, dass. wir aber trotzdem stets die einzelnen Wirkungsphasen zu erkennen vermögen. Ferner sehen wir, dass hier die Exstirpation des Ganglion die gleiche Wirkung hat wie oben dessen Lähmung. 
Dieselben Resultate erhalten wir, wenn wir anstatt der Reflexerregbarkeit, die "direkte Frregbarkeit“ zum Gegenstande unserer Beobachtung machen.

Tabelle 18.

Helix ohne Cerebralganglion mit $20 \mathrm{~g}$ belastet. Direkte Erregung durch Wechselstrom.

\begin{tabular}{c|c|c|c}
\hline Pause & $\begin{array}{c}\text { R.-A. } \\
\mathrm{cm}\end{array}$ & Einstellung & nach Schluss \\
\hline 1 Minute zwischen & 5,5 & 12 & 12,3 \\
je 2 Ablesungen & 5,75 & 11,5 & 11,5 \\
der ganzen Tabelle & 5,75 & 11,5 & 11,5
\end{tabular}

Kokain 2,5\% auf die Pedalganglien

$$
\begin{array}{l|l|l}
5,75 & 10 & 10,5 \\
6 & 9,4 & 10
\end{array}
$$

Kokainkristalle auf die Pedalganglien

$$
\begin{array}{l|l|l}
6 & 8,9 & 10 \\
6,5 & 7,2 & 7,9
\end{array}
$$

Nun wird etwas gewartet (3 Minuten). Der Tonus beginnt zu steigen.

\begin{tabular}{c|c|c}
\hline $\begin{array}{c}\text { R.-A. } \\
\text { cm }\end{array}$ & Einstellung & nach Schluss \\
\hline \begin{tabular}{c|c}
6,5 \\
4,5
\end{tabular} & $\begin{array}{l}8,8 \\
8\end{array}$ & $\begin{array}{l}8,8 \\
8\end{array}$
\end{tabular}

Diesem Beispiele könnte ich zwei weitere an die Seite stellen, bei denen die Ganglien nach erreichtem Maximum exstirpiert wurden: Gleiches Resultat wie durch Lähmung.

Auf der anderen Seite habe ich auf die Pedalganglien Stoffe wirken lassen, denen notorisch eine erregende Wirkung zukommt, vor allem Kochsalz. Galt es nämlich einmal das Verhalten der Muskulatur kennen zu lernen, deren "Zentrum" im Zustande der Erregung war, so musste andererseits der Beweis erbracht werden, dass unmittelbar das Kokain nur den Tonus beherrsche, und fur die gesteigerte Erregbarkeit nicht eine prodromale erregende Wirkung des Kokains verantwortlich zu machen sei. Wäre dem nämlich so, so müsste auch Applikation von Kochsalz auf die Pedalganglien die Erregbarkeit steigern. Ich komme auf diese Fragen später zurück. 
U ntersuchungen zur Physiologie des Nervensystems bei Pulmonaten. II. 557

Tabelle 19.

Tier ohne Cerebralganglion. Direkte Erregharkeit durch

Wechselstrom.

\begin{tabular}{c|c|c|c}
\hline \hline Pause & $\begin{array}{c}\text { R.-A. } \\
\mathrm{cm}\end{array}$ & Einstellung & nach Schluss \\
\hline \multirow{2}{*}{ je 1 Minute } & 4,75 & 5 & 6 \\
5 & 5,2 & 5,2
\end{tabular}

NaCl-Kristall auf die Pedalganglien

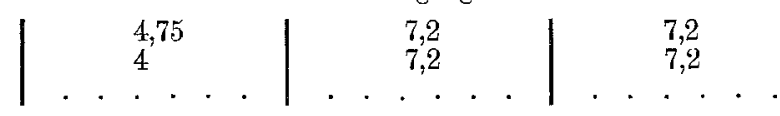

Bei $3 \mathrm{~cm}$ Abstand lässt sich etwa Erregbarkeit nachweisen; dabei reagiert der Muskel sehr langsam, also wie der eines ganglienlosen Tieres, beantwortet aber Reizung der Pedalganglien in sehr ausgesprochener Weise. Diesen Effekt kann man natürlich noch steigern.

\section{Das Cerebralganglion.}

a) Der unmittelbare Einfinss des Cerebralganglion anf die Reflexe und die direkte Erregbarkeit.

Ich habe in meiner Arbeit über Aplysia (Zeitschr. f. Biol. Bd. 41 S. 215 u. 223. 1901.) gezeigt, dass die Exstirpation des Cerebralganglion einen sehr wesentlichen Einfluss auf die Lokomotion sowohl als auf die Reflexerregbarkeit hat. Dieser Eingriff bedingt bei Aplysia erhöhten Ausschlag, nach gleicbförmiger Reizung. Es ist leicht, den Versuch zu wiederbolen und diese Verbältnisse, in der uns nunmehr vertrauten Weise, durch Zahlen auszudrücken. Ich will den Versuch in etwas erweiterter Form mitteilen: Nachdem ich einmal die Ausschlagsböhe des normalen Tieres festgestellt hatte, habe ich vorab das Cerebralganglion in seiner Medianebne - eigentlich die Cerebralkommissur mit einer feinen Schere ("Fingerschere" nach Bethe) durchtrennt. Ich musste mir nämlich sagen, dass die Einwirkung des Cerebralganglion doch auf irgendwelchem Leitungsvorgang beruhen k önne. Ich weiss wohl, dass der Versuch an sich wenig beweist, da er sich ja nur auf die Kommunikation der rechten Seite mit der linken beziebt; immerhin war zu denken, dass, wenn überhaupt ein Leitungsvorgang (im Sinne einer Kommunikation) in Betracht komme, jede Unterbrechung auch nur eines Teiles der Leitungsbahn die Funktion des Ganglion hätte beeinträchtigen müssen. Eine derartige Beeinträchtigung hat sich (in drei Versuchen) nicht nachweisen lassen. 
Tabelle 20.

Normale Helix mit $7 \mathrm{~g}$ belastet. Reflexerregung durch Einzelschläge.

\begin{tabular}{c|c|c}
\hline \hline Pause. & Einstellung & nach Schluss \\
\hline \multirow{2}{*}{ je 1 Minute } & 1 & 3 \\
& 1 & 2,8 \\
& 1,2 & 3,2
\end{tabular}

Durchtrennung des Cerebralganglion in der Sagittalebene

\begin{tabular}{|c|c|c|}
\hline je 1 Minute & $\begin{array}{l}1,7 \\
1 \\
1 \\
2\end{array}$ & $\begin{array}{l}2,0 \\
2,2 \\
2,5 \\
3,6\end{array}$ \\
\hline \multicolumn{3}{|c|}{ Exstirpation des medianen Ganglienzellpolsters } \\
\hline je 1 Minute & $\begin{array}{l}1,3 \\
1,3 \\
1,6 \\
2 \\
2,5 \\
2,5 \\
2,1\end{array}$ & $\begin{array}{l}3,4 \\
5,2 \\
6 \\
7 \\
7,7 \\
8 \\
7\end{array}$ \\
\hline \multicolumn{3}{|c|}{ Totalexstirpation } \\
\hline & $\stackrel{2}{2,5}$ & $\begin{array}{l}6,8 \\
7\end{array}$ \\
\hline
\end{tabular}

Man ersieht zweierlei aus diesen Zahlen: 1. Nach Exstirpation des Cerebralganglion ist die Arbeit, die der Muskel auf gleichen Reiz hin leistet, grösser als in der Norm. 2. Für die „hemmende Funktion scheint der mediane Teil des Ganglion, der durch das Pigment seiner Ganglienzellen sich von dem übrigen Gewebe abhebt, verantwortlich zu sein. Im besonderen sei noch auf die Zunahme der Ausschläge im Verlauf der Versuche hingewiesen.

Nicht nur die Arbeitsleistung ist eine relativ grössere, auch die Erregbarkeit steigt nach Exstirpation des Cerebralganglion.

Tabelle 21.

Normales Tier, $15 \mathrm{~g}$ Belastung. „Direkte Reizung“ durch Wechselströme.

\begin{tabular}{c|c|c|c}
\hline \hline Pause & $\begin{array}{c}\text { R.-A. } \\
\mathrm{cm}\end{array}$ & Einstellung & nach Schluss \\
\hline je 1 Minute & 4 & 8,2 & 8,2 \\
& 3,75 & 9 & 9,3
\end{tabular}




\begin{tabular}{l|c|c|c}
\hline Pause & $\begin{array}{c}\text { R.-A. } \\
\mathrm{cm}\end{array}$ & Einstellung & nach Schluss \\
\hline
\end{tabular}

\begin{tabular}{l|l|l|r}
\hline \multicolumn{4}{c}{ Exstirpation des Cerebralganglion } \\
je 1 Minute & 3,75 & 4 & 8,7 \\
& 4,0 & 6,2 & 7,5 \\
& 5,0 & 9,2 & 11,0 \\
& 5,2 & 8,5 & 9,1 \\
5,5 & 6,5 & 6,5
\end{tabular}

Die Unruhe, die höhere Beweglichkeit, ja die nicht inhibierbare Lokomotion des cerebrallosen Tieres haben wir hier in ihre Elemente zerlegt: höhere Erregbarkeit, und höhere Arbeitsleistung bei gleichem äusseren Reize (zwei Erscheinungen, die nicht unbedingt, wenn auch meist, Hand in Hand gehen; vgl. weiter unten). Mit anderen Worten: Die Muskeln eines Tieres ohne Cerebralganglion verhalten sich bezüglich der Erregbarkeit zu einem normalen, wie tonusarme Muskeln zu tonusreichen. Dabei sprechen die Zahlen in keiner Weise dafür, dass für die Erscheinung geringerer Tonus verantwortlich zu machen sei. (Etwas anderes ist es mit der allmählichen, sekundären Zunahme der Ausschlagshöhe, die wahrseheinlich durch Tonusminderung nach Widerstandsüberwindung herbeigeführt wird.)

\section{b) Beeinflusst das Cerebralganglion den Tonus?}

Es erhebt sich ganz von selbst die Frage: Hat vielleicht doch das Cerebralganglion einen unmittelbaren Einfluss auf den Tonus und dadurch nur mittelbar auf die Erregbarkeit. Zur Beantwortung dieser Frage habe ich unter analogen Versuchsbedingungen wie in Mitteilung I das, seines Cerebralganglion beraubte Tier, mit dem normalen verglichen.

a) Belastung: Wenn wir - so sahen wir in Mitteilung I einen Schneckenmuskel an unserer Wage belasten, so dehnt er sich und entlastet sich dadurch. Wir haben gesehen, dass bei dieser, den Innendruck des Tieres regulierenden Funktion einmal „die Ganglien" eine bedeutende Rolle spielen, sodann aber, dass diese Rolle in hohem Grade von der gewählten Ausgangsbelastung abhängt. Diese Tatsachen können uns hier zum Prüfstein dienen für die Frage, ob das Cerebralganglion an jener Regulierung beteiligt sei oder nicht. 
Tabelle 22.

Je ein normales und ein cerebralloses Tier mit 5 g belastet.

(Niedere.Belastung.)

\begin{tabular}{c|c|c}
\hline Zeit & $\begin{array}{c}\text { Normales } \\
\text { Tier } \\
\mathrm{g}\end{array}$ & $\begin{array}{c}\text { Ohne } \\
\text { Cerebralganglion } \\
\mathrm{g}\end{array}$ \\
\hline $\mathrm{12} \mathrm{h} 24^{\prime}$ & 5 & 5 \\
$12 \mathrm{~h} 30^{\prime}$ & 4,2 & 3,2 \\
$12 \mathrm{~h} 35^{\prime}$ & 3,2 & 2,5 \\
$12 \mathrm{~h} 38^{\prime}$ & 2,9 & 2,2
\end{tabular}

Obwohl diese Werte nicht genau übereinstimmen (was ja auch kaum zu erwarten wäre, da individuelle Verschiedenheiten stets vorkommen), so kann man doch sagen, beide Tiere entlasten sich gleich schnell, vor allem entlastet sich das cerebrallose nicht langsamer als das normale (hier sogar etwas schneller). Nun haben wir als "Ganglienwirkung" bei niederer Belastung aber gerade $\mathrm{Be}$ schleunigung der Entlastung kennen gelernt, eine Funktion, an der das Cerebralganglion sicher nicht beteiligt ist.

Das klarere Bild geben natürlich Versuche mit "Hochbelastung", da wir ja sahen, dass unter dieser Bedingung die Ganglienwirkung eine zwiefältige ist: erst Beschleunigung der Entlastung, bis zu einem gewissen Punkte, damn aber Hemmung dieser Funktion, so dass zuletzt das ganglienlose Tier sich stets tiefer einstellt als das normale. Ich habe daher meine eigentlichen hierhergehörigen Untersuchungen unter Anwendung von "Hochbelastung" angestellt. Nach Wall möglichst gleich grosser Tiere ist es mir in vier Fällen gelungen zu zeigen, dass cerebralloses und normales Tier sich Belastungen gegenüber durchaus gleich verbalten.

Hier genüge wiederum ein einziges Protokoll.

Tabelle 23.

Je ein normales und cerebralloses Tier mit 25 g belastet.

(Hochbelastung.)

\begin{tabular}{c|l|l}
\hline Zeit & $\begin{array}{c}\text { Normales } \\
\text { Tier } \\
\mathrm{g}\end{array}$ & $\begin{array}{c}\text { Cerebralloses } \\
\text { Tier } \\
\mathrm{g}\end{array}$ \\
\hline $11 \mathrm{~h} 33^{\prime}$ & 25 & 25 \\
$11 \mathrm{~h} 33^{1} / \mathrm{h}^{\prime}$ & 15,1 & 15 \\
$11 \mathrm{~h} 34^{\prime}$ & 13 & 12 \\
$11 \mathrm{~h} 35^{\prime}$, & 13 & 11,5 \\
$11 \mathrm{~h} 39^{\prime}$, & 10 (konstant) & 10 (konstant)
\end{tabular}


Exstirpiert man nun dem "normalen Tiere" das Cerebralganglion, so ändert dieser Eingriff an der "Konstanz" (oder wenn "Schwankungen" auftreten am Schwankungsminimum) gar nichts. Natürlich baben sich kleine Abweichungen auch bei meinen vier Versuchen ergeben, doch liess sich zeigen, dass sie lediglich individueller Natur waren, da einmal das cerebrallose, das andere Mal aber das normale Tier etwas schneller war. Was die Hauptsache ist: eine spätere Umkehr des Verhältnisses der Geschwindigkeiten hat sich nie ergeben. (Dass diese Versuche, der grossen Erregbarkeit cerebralloser Tiere wegen, mit grosser Vorsicht ausgeführt werden müssen, braucht kaum erwähnt zu werden.)

An der Regulierung des Widerstandes gegen Ausdehnung, oder der Anpassung an Belastung (Innendruck) ist das Cerebralganglion durchaus unbeteiligt.

B) Tonuszunahme a uf künstliche Entlastung. Ich habe in Mitteilung I gezeigt, dass die Regulierung des tonischen Muskelzustandes nicht ausschliesslich durch Hemmung oder Beschleunigung der Ausdehnung, sondern gegebenen Falles auch durch Erzeugung von Verkürzung bedingt werden kann; dann nämlich, wenn wir einen durch Belastung gedehnten Muskel schnell entlasten. Da wir sahen, dass das Cerebralganglion den Grad der Verkürzung auf Erregung hin zu regulieren vermöge, so lag es nabe zu fragen, ob es auf die Verkürzung auf Entlastung auch jenen entscheidenden Einfluss babe, den wir in Mitteilung I "den Ganglien" haben zusprechen müssen.

Das Folgende sind die Ergebnisse von an zwölf Tieren ausgeführten Versuchen. Vorab wurden cerebrallose Tiere in genau der nämlichen Weise belastet, und nach einer Zeit des Wartens auf $5 \mathrm{~g}$ entlastet, wie bei den in Mitteilung I angeführten Versuchen, so dass ich unmittelbar mit diesen die neuen Resultate vergleiche (siehe Tab. 24 a und $24 \mathrm{~b}$ auf S. 562).

Schon aus dieser Tabelle lässt sich ein Untersehied zwischen normalem und cerebrallosem Tiere nicht nachweisen, während der Unterschied zwischen diesem und dem ganglienlosen eher beträchtlicher zu sein scheint. Ich sage: scheint, und zwar aus folgendem Grunde: Die bedeutende Erregbarkeit des cerebrallosen Tieres bedingt natürlich eine technische Schwierigkeit: Damit ein Teil der abzulesenden Steigerung nicht schon während der Entlastung vor sich geht, oder doch, damit dieser Teil keine allzugrosse Fehlerquelle 
Tabelie 24 a.

\begin{tabular}{c|c|c}
\hline & \multicolumn{2}{|c}{$\begin{array}{c}\text { Es steigt nach Entlastung auf } 5 \mathrm{~g} \\
\text { der Zeiger des }\end{array}$} \\
\hline Belastung & $\begin{array}{c}\text { cormalen Tieres } \\
\text { (Mitt. I S. 208) } \\
\text { um g }\end{array}$ & $\begin{array}{c}\text { cerebrallosen } \\
\text { Tieres } \\
\text { um g }\end{array}$ \\
\hline 20 & 0,2 & 0 \\
25 & 0,5 & 0 \\
20 & 0,2 & 0,3 \\
25 & 0,8 & 0 \\
20 & 1,0 & 0,5 \\
25 & 1,5 & 0,5 \\
20 & 0,5 & 0,6 \\
25 & 0,6 & 0,6 \\
20 & 1,2 & 0,6 \\
25 & 2,5 & 1,9 \\
20 & 1,8 & 1,4 \\
25 & 2,2 & 1,9
\end{tabular}

Tabelle $24 \mathrm{~b}$.

Gleiche Tiere. "Hochbelastung".

\begin{tabular}{c|c|c|c}
\hline \hline \multirow{3}{*}{ Belastung } & $\begin{array}{c}\text { Es wird gewartet, } \\
\text { bis der Zeiger zeigt }\end{array}$ & $\begin{array}{c}\text { Nach Entlastung auf } 5 \mathrm{~g} \text { steigt der } \\
\text { Zeiger des }\end{array}$ \\
\cline { 3 - 4 } & $\mathrm{g}$ & $\begin{array}{c}\text { normalen } \\
\text { Tieres } \\
\text { un g }\end{array}$ & $\begin{array}{c}\text { cerebrallosen } \\
\text { Tieres } \\
\text { um g }\end{array}$ \\
\hline 40 & 17 & 2,5 & 2,2 \\
40 & 23 & 5,0 & 3,0 \\
40 & 27 & 4,0 & 3,3 \\
50 & 27 & 6,5 & 4,2 \\
50 & 30 & 6,5 & 3,5
\end{tabular}

bildet, habe ich in früheren Versuchen ziemlich schnell, wenn auch niemals ruckweise entlastet. Dies würde beim cerebrallosen Tier nicht gehen; eine ergiebige Kontraktion auf Erregung würde das Resultat sein. Ich habe wesentlich langsamer entlasten müssen, und den grösseren Verlust an "Tonuszunahme" kann man denn auch aus der Tabelle ersehen. Was wir jedoch beweisen wollen, ist, dass normales und cerebralloses Tier gleiche Art der Zunahme der abgelesenen Werte zeigen, und hierzu genügt der Versuch. Ich habe noch eine Reihe weiterer Versuche angestellt, die speziel den folgenden Satz mit noch grösserer Sicherheit beweisen sollen: Ein belasteter Muskel verkürzt sich aktiv auf Entlastung. Diese Verkürzung wird, war die Belastung (Dehnung) eine geringe, durch die Pedalganglien, nicht 
Untersuchungen zur Physiologie des Nervensystems bei Pulmonaten. II. 563

aber durch das Cerebralganglion verringert (gehemmt). Dieser Satz hat für unsere spätere Betrachtung Bedeutung.

Ein cerebralloses Tier wird mit $25 \mathrm{~g}$ belastet, der Zeiger fällt bis $21 \mathrm{~g}$. Nun wird auf $5 \mathrm{~g}$ entlastet und die Steigerung wie oben in Gramm abgelesen. Ein - bedeutet, die Ablesung sei infolge ungeschickter Handbewegung usw. ungültig; sie muss jedoch angegeben werden, da sie zur Gesamtdehnung beiträgt. Ich gebe nur die Zahlen der Steigerung über $5 \mathrm{~g}$ an.

0,1

Nun werden die Pedalganglien exstirpiert.

$$
\begin{aligned}
& 0,6 \\
& 0,6
\end{aligned}
$$

Mit anderen Worten: die Pedalganglien vermögen nach niederer Belastung die "Tonuszunahme", d. i. Verkürzung des Muskels, nach Entlastung herabusetzen.

Eine Fehlerquelle scheint dieser Versuch mir nicht zu bergen, denn einmal würde Erregung durch Entlastung den höheren Ausschlag beim cerebrallosen Tiere bedingen, und dann ist, wie mir scheint, der Sprung von 0,1-0,6. charakteristisch genug. Dabei erwähne ich ausdrücklich, dass in allen Ablesungen die Kurbel gleich langsam bewegt wurde.

Um auch das normale Tier zu der Vergleichung heranziehen zu können, bin ich folgendermassen verfahren: Der Muskel wurde stets mit $20 \mathrm{~g}$ belastet, und nachdem der Zeiger um $5 \mathrm{~g}$ gefallen war, auf $5 \mathrm{~g}$ entlastet. Man erhält folgende Erhebungen über $5 \mathrm{~g}$ :

Normales Tier

$$
\begin{aligned}
& 0,5 \mathrm{~g} \\
& 0,2 " \\
& 0,4 " \\
& 0,3 "
\end{aligned}
$$
Gleiches Tier nach
Exstirpation d. Cerebral

$0.3 g$

0,2

0,3 ,
Gleiches Tier

ohne Ganglien

$$
\begin{aligned}
& 0,6 \mathrm{~g} \\
& 0,7 " \\
& 0,8 " \\
& 1,2 "
\end{aligned}
$$

Das umgekehrte Verhalten ergibt sich, wenn wir die Ganglien nach "Hochbelastung" (50 g) exstirpieren. Hat man durch längere Fortsetzung des Versuches die Ausschläge des normalen Tieres auf 4-5 g gebracht, so ändert auch jetzt Exstirpation des Cerebrale nichts, während Exstirpation aller Ganglien den Aussehlag auf 2,1 $\mathrm{g}$ reduziert. 
Es dürfte sich - nach unserer Kenntnis vom Tonus - vou selbst verstehen, dass bei weitem nicht alle Protokolle sich so typisch verhalten, wie die obigen. Ist der Tonusgrad des betreffenden Tieres an sich gering (Anwendung hohen Wärmegrades beim Lösen des Winterschlafes etwa), so wird der "Umkehrpunkt" bald erreicht; der Punkt also, bei dem normales und ganglienloses Tier den gleichen Ausschlag geben, und von dem an das normale am stärksten reagiert. $\mathrm{Zu}$ all diesen Versuchen gehört nicht nur die Kenntnis des tonischen Verhaltens der Muskulatur, sondern jeweilig eine grosse Anzahl von gleichen Versuchen, um überhaupt etwas behaupten zu können. Auf Grund einiger Kenntnis des tonischen Verhaltens, auf Grund einer Reihe von Ergebnissen, die gleichlautend sind, kann ich sagen: Die Dämpfung des Ausschlages auf Entlastung nach "niederer Belastung" sowie die Steigerung des Ausschlages nach "Hochbelastung" sind Funktionen der Pedalganglien, das Cerebralganglion ist hieran im wesentlichen unbeteiligt Im wesentlichen unbeteiligt, weil die Methode (oder der hierzu angewandte Apparat) nicht fein genug ist, um kleine Differenzen nachweisen zu können. Auch hier muss als bester Beweis dafür, dass das Cerebralganglion ohne jeden Einfluss ist, der Umstand angesehen werden, dass die Ausschläge bald beim normalen, bald beim cerebrallosen Tiere unter gleichen Bedingungen stärker ausfallen.

y) Ich habe oben gesagt, dass man auch beim cerebrallosen Tiere den Tonus der einen Tierhälfte, durch Belastung und Entlastung der anderen beeinflussen kann, wenn beide nur noch durch das Zentralnervensystem kommunizieren. Wenn wir auch absichtlich grosse Reaktionen im registrierenden Teil des Tieres hintangehalten haben, so genuggt uns der Versuch dort, um sagen zu dürfen: Auch ohne Anwesenheit des Cerebralganglion reagiert eine Tierhälfte tonisch a f tonische Veränderungen in der and eren.

Vgl. Tab. 8: Auf Belastung mit $20 \mathrm{~g}$ der einen Hälfte sinkt in der registrierenden der Tonus von 2,2 bis $1,5 \mathrm{~g}$ und steigt nach Entlastung auf $3,4 \mathrm{~g}$.

Genug, alle diese Versuche zeigen eine deutliche Abweichung im Verhalten des Cerebrallosen, verglichen mit demjenigen des Ganglienlosen. Sie erlauben mir hingegen nicht, einen solchen Unterschied, als zwischen normalem und cerebrallosem Tiere vorhanden, anzunehmen. 
d) Kokainisiert man das auf dem Darm (in normaler Lage) sich befindende Cerebralganglion bei einem Tiere, welches sich an der Wage in tonischer "Konstanz" befindet, so tritt ein Tonusfall nicht ein.

Man hat natürlich dafür zu sorgen, dass kein Kokain auf die Pedalganglien gelangt. Zur Kontrolle dient Farbstoff (Neutralrot) in der Kokainlösung.

Nach alledem sehe ich mich zu dem Schlusse berechtigt, dass das Cerebralganglion auf die Regulierung des Tonus keinen nachweisbaren Einfluss hat: eine solche ist lediglich Funktion der Pedalganglien.

\section{c) Wie arbeiten Tonus und Cerebralganglion gemeinsam an der Regulierung der Erregbarkeit.}

Wir haben gesehen, dass die Schnecke über zwei Vorrichtungen verfügt, ihre Erregbarkeit und Muskelleistung, also ihre Reflexe und ihre Lokomotion, zu regulieren: 1. durch den Tonus, also mittelbar durch die Pedalganglien; 2. unmittelbar durch das Cerebralganglion, welches seinerseits auf den Tonus keinen Einfluss hat.

Wie wird nun in diesem Staate mit zwei Häuptern Anarchie vermieden, wer ist oberster Befehlshaber? Um diese Frage beantworten zu können, musste untersucht werden, welchen Einfluss alle diejenigen Agentien, die den Tonus herabsetzen, auf die Erregbarkeit des normalen Tieres, verglichen mit derjenigen des cerebrallosen, haben.

Kommen wir vor allem auf die Versuche zurück, bei denen der nämliche Muskel unter verschiedener Belastung auf seine (direkte) Erregbarkeit hin geprüft wird, und deren Resultat, auch für das normale Tier, ich schon teilweise mitgeteilt habe.

\section{Tabelle 25.}

Normales Tier mit $7 \mathrm{~g}$ belastet. Direkte Erregbarkeit durch Wechselströme.

\begin{tabular}{c|c|c|c}
\hline Pause & $\begin{array}{c}\text { R.-A. } \\
\mathrm{cm}\end{array}$ & Einstellung & nach Schluss \\
\hline \multirow{2}{*}{ je 1 Minute } & 1 & $\begin{array}{c}4,7 \\
4,3\end{array}$ & $\begin{array}{c}5,3 \\
4,3\end{array}$
\end{tabular}

Dasselbe Tier mit $20 \mathrm{~g}$ belastet 


\begin{tabular}{l|c|c|c}
\hline Pause & $\begin{array}{c}\text { R.*A. } \\
\mathrm{cm}\end{array}$ & Einstellung & nach Schluss \\
\hline
\end{tabular}

Exstirpation des Cerebralganglion, Entlastung auf 2,5 g

je 1 Minute

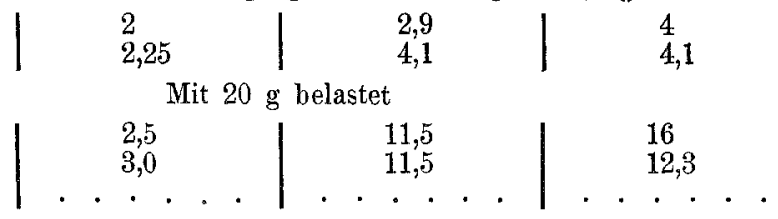

Diesem Protokolle lässt sich - so scheint mir - mancherlei entnehmen: Bei der weitgehenden Verminderung des Tonus, die wir durch die Belastung erzielt haben, steigt die Erregbarkeit, ob nun das Cerebralganglion vorhanden ist oder nicht. Mehr noch: Das hoch belastete normale Tier ist erregbarer als das niedrig belastete cerebrallose! Jenes gibt bei R.-A. 2,5 cm einen deutlichen, dieses bei R.-A 2,25 aber gar keinen Ausschlag. Es hat also den Anschein, als sei in diesem Falle der Tonus der mächtigere Regulator. Deutlich zeigt der Versuch auch die Summierung des Ausschlages, dann nämlich, wenn beide Regulatoren in gleichem Sinne wirken. Das cerebrallose Tier erreicht, mit $20 \mathrm{~g}$ Ausgangsbelastung, die grösste Erregbarkeit: R.-A. $3 \mathrm{~cm}$ und darüber. (Ich habe die letzte Grenze nicht bestimmt.)

Natürlich beweist der Versuch die Suprematie des Tonus nur für gewisse Fälle, dann nämlich, wenn der Eingriff ein energischer ist, also hier bei Ausdehnung des Muskels.

Um auch unter Bedingungen experimentieren zu können, die einmal, wie wir sahen, bessere Vergleichswerte liefern, dann aber weniger extrem in ihrem Eingriffe sind, wurden alle jene Versuche, die ich am cerebrallosen (oder ganglienlosen) Tiere angestellt habe, am normalen wiederholt.

a) "Halbtierversuch". Die Beschreibung der Versuchsanordnung braucht hier nicht wiederholt zu werden (vgl. Tab. 8).

(Siehe Tal, 26 auf S. 567.)

Diesem Tiere habe ich dann das Cerebralganglion exstirpiert und dabei die positiven Resultate erhalten, die ich oben mitteilte.

Obwohl also die nervöse Kommunikation zwischen beiden Tierhälften vorhanden ist, obwohl ein deutlicher Tonusfall im registrierenden Muskel dies dokumentiert, ist von einer gesteigerten Arbeitsleistung des registrierenden Muskels keine Rede. Die Strecke, um die sich 
Untersuchungen zur Physiologie des Nervensystems bei Pulmonaten. II. 567

Tabelle 26.

Tier mit allen Ganglien. Reflexerregbarkeit des registrierenden Teils durch Einzelschläge.

\begin{tabular}{|c|c|c|c|}
\hline \multirow{2}{*}{$\begin{array}{c}\text { Belastete Tierhälfte } \\
\text { trägt } \\
\mathrm{g}\end{array}$} & \multirow{2}{*}{ Zeit } & \multicolumn{2}{|c|}{ Registrierende Tierhälfte zeigt } \\
\hline & & Einstellung & nach Schluss \\
\hline 0 & $\begin{array}{l}9 \text { h } 46^{\prime} \\
9 \text { h } 48^{\prime} \\
9 \text { һ } 50^{\prime} \\
9 \text { Һ } 52^{\prime}\end{array}$ & $\begin{array}{l}2,2 \\
2,3 \\
2,2 \\
2,5\end{array}$ & $\begin{array}{l}5 \\
4,8 \\
4,5 \\
4,5\end{array}$ \\
\hline 20 & 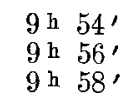 & $\begin{array}{l}1,9 \\
1,2 \\
1,3\end{array}$ & $\begin{array}{l}3,9 \\
2,9 \\
2,2\end{array}$ \\
\hline 0 & $\begin{array}{l}10 \mathrm{~h} \\
10 \mathrm{~h} 2^{\prime}\end{array}$ & $\begin{array}{l}3,5 \\
2,5\end{array}$ & $\begin{array}{l}6 \\
4,9\end{array}$ \\
\hline
\end{tabular}

der Muskel zusammenzieht, ist fast in allen Fällen gleich, und wenn es aussieht, als sei umgekehrt der tonusreichere Muskel erregbarer, so muss gesagt werden, dass einmal die Differenzen viel zu klein sind, um etwas $z u$ beweisen, und dass andrerseits in vielen anderen Fällen eine derartige Differenz sich nicht als konstant erwiesen hat. Zum Beweise diene folgendes Protokoll:

Tabelle 27.

Normales Tier. "Halbtierversuch". Reflexerregung durch Einzelschläge.

\begin{tabular}{c|c|c|c}
\hline $\begin{array}{c}\text { Belastete Hälfte } \\
\text { trägt } \\
\mathrm{g}\end{array}$ & Zeit & \multicolumn{2}{|c}{ Registrierende Hälfte zeigt } \\
\cline { 2 - 4 } & Einstellung & nach Schluss \\
\hline \multirow{2}{*}{0} & $10 \mathrm{~h} 27^{\prime}$ & 6 & 7,3 \\
20 & $10 \mathrm{~h} 29^{\prime}$ & 4,9 & 6,2 \\
& $10 \mathrm{~h} 31^{\prime}$ & 4,3 & 5,2 \\
0 & $10 \mathrm{~h} 34^{\prime}$ & 5,1 & 6,2 \\
& $10 \mathrm{~h} 36^{\prime}$ & 4,8 & 5,9 \\
& $10 \mathrm{~h} 38^{\prime}$ & 4,0 & 4,8 \\
& $10 \mathrm{~h} 39^{\prime}$ & 4,5 & 5,0 (abgefangen) \\
0 & $10 \mathrm{~h} 41^{\prime}$ & 4,0 & 5,1 \\
& $10 \mathrm{~h} 46^{\prime}$ & 5 & 5,9
\end{tabular}

Hier also haben wir genug Fälle, die eine Vergleichung zulassen und es ergibt sich absolutes Übereinstimmen der Arbeitsleistung, ob die andere Tierhälfte belastet ist oder nicht. Auch hier erhielt ich die mitgeteilten deutlichen Unterschiede, sobald ich das Cerebralganglion exstirpierte. 
B) Wärme: Noch interessantere Tatsachen bin ich in der Lage über Versuche mit Wärme mitzuteilen.

Die Versuchsanordnung wurde auch für diesen Fall oben beschrieben.

Tabelle 28,

Normales Tier im Zylinder des Blechkastens,

der zu Wärmeversuchen dient. Reflexerregbarkeit durch

Einzelschläge (Arbeitsleistung).

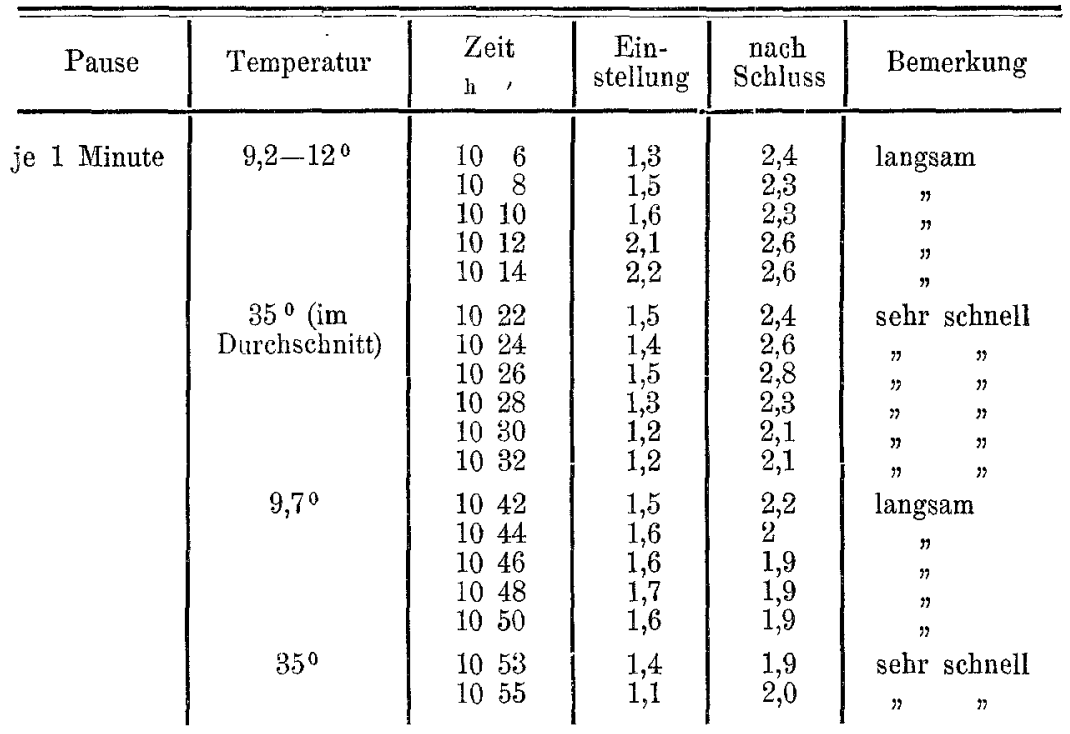

Wir sehen also, dass eine geradezu auffallende Gleichheit in der von dem Muskel geleisteten Arbeit besteht, ob er nun bei einer Temperatur von etwa $10^{\circ}$ orler aber einer solchen von etwa $35^{\circ}$ gereizt wurde. Hier wäre eine Kurve lehrreich gewesen: bei gleicher Höhe würde nämlich die Wärmekurve wesentlich steiler verlaufen als die Kältekurve. Beobachtet man bei den einzelnen in der Wärme erfolgenden Ausschlägen den Zeiger, so hat man den Eindruck, als würde ein ganz beträchtlicher Mehrausschlag erfolgen als in der Kälte; erstaunt sieht man aber, wie in gleicher Höhe der Zeiger wie gebremst stehen bleibt, wo er auch eben in der Kälte, seiner trägen Bewegung ein Ende bereitete. Entfernt man das Cerebralganglion, so fällt diese Hemmung weg, und man erbält die Werte, die ich oben mitgeteilt habe. Diese Resultate haben sich bei gleicher Anordnung fünfmal obne jede Ausnahme bestätigen lassen.

Ein ganz anderes Ergebnis erhalten wir, wenn wir statt der 
Untersuchungen zur Physiologie des Nervensystems bei Pulmonaten. II. 569

Arbeitsleistung bei konstantem Reiz die Erregbarkeit bei verschiedenem Rollenabstand feststellen.

Tabelle 29.

Normales Tier im "Wärmekasten". Direkte Erregbarkeit auf Wechselstöme.

\begin{tabular}{c|c|c|l}
\hline \multirow{2}{*}{ Temperatur } & $\begin{array}{c}\text { R.-A. } \\
\mathrm{cm}\end{array}$ & Einstellung & nach Schluss \\
\hline \multirow{2}{*}{$13-15^{0}$} & 5,75 & 5,0 & 5,1 \\
& 6 & 5,0 & 5,0 unerregbar \\
40 & 6 & 5,0 & 5,5 \\
& 6,75 & 3,8 & 4,0 \\
\multirow{3}{*}{$15^{0}$} & $(5,5$ & 3,5 & $5, \mathbf{1})$ \\
& 5,5 & 3,9 & 5,9 \\
& 6 & 3,6 & 3,6
\end{tabular}

Aus diesem Versuche sehen wir, dass die Erregbarkeit auch beim normalen Tiere (und bei Reizung der Bahnen), in der Wärme grösser wird; aber auch bei dieser Anòrdnung zeigt sich's, dass mit der Erregbarkeit sich nicht die Ausschlagshöhe, also die Arbeitsleistung steigert: $\quad 40^{\circ}$ R.-A. $5,5 \mathrm{~cm}$ Ausschlag $3,5-5,1$

$$
15^{0} \Rightarrow 5,5 \Rightarrow \quad 3,0-5,9 \text { (siehe oben). }
$$

Aus dargetanen Gründen habe ich auch durch Einzelschläge für Bahnenreizung diesen Satz bestätigt.

Tabelle 30.

Normales Tier im "Wärmekasten". Direkte (Bahnen-)Reizung durch Einzelschläge.

\begin{tabular}{c|c|c}
\hline Temperatur & Einstellung & nach Schluss \\
\hline \multirow{2}{*}{$13-15^{0}$} & 3 & 5,4 \\
& 3 & 5,2 \\
35 & 3,7 & 5,1 \\
& 3,5 & 5,1 \\
& 4,1 & 4,9 \\
& 3 & 4,9
\end{tabular}

(Dieser Versuch wurde nur einmal ausgeführt, da er, verglichen mit den entsprechenden Reflexversuchen, nichts Neues zeigt.)

Die einzelnen Ausschläge sind in der Wärme also auch bei dieser Anordnung eher kleiner als grösser: solange nämlich das Tier noch über sein Cerebralganglion verfügt. Entfernt man dieses, so werden auch die Ausschläge in der Wärme grösser, wie wir das gesehen haben. 
Alle diese Versuche beweisen übereinstimmend, dass, wenn wir durch äussere (Wärme) oder innere (Halbtier) Agentien den Tonus vermindern, ohne dabei den Muskel selbst weitgehend zu beeinflussen, das Cerebralganglion nicht so sehr die Erregbarkeit als vielmehr die Ausschlagshöhe der Kontraktion, d. h. die Arbeitsleistung, zur Norm zu reduzieren imstande ist. Erst wenn die Tonusdifferenz eine grosse wird, scheint der Tonus als Regulator die Vorherrschaft zu erlangen.

d) Die regulatorische Funktion des Cerebralganglion je nach seinem Zustande.

Es wäre nun gänzlich verfehlt, wollten wir glauben, das Rätsel der Regulation von Erregbarkeit und Lokomotion gelöst zu haben, derart etwa, dass bei stärkeren, die Muskein unmittelbar affizierenden Eingriffen der Tonus, sonst aber ausschliesslich das Cerebralganglion die Arbeitsleistung der Muskulatur reguliere, und dass auf Grund dieses Verhältnisses etwa jede Reaktion, jede "Handlung" des Tieres vorauszusagen sei. Die Ganglien sind Regulatoren, allein sie selbst regulieren die ihnen unterstellten Funktionen je nach dem Zustande, in dem sie selbst verkehren. Für die Pedalganglien habe ich dies schon gezeigt; für das Cerebralganglion sei mir gestattet, es jetzt darzutun.

a) Kokainisierung des Cerebralganglion.

Tabelle 31 .

Normales Tier mit $20 \mathrm{~g}$ belastet. Direkte Erregbarkeit durch Wechselströme.

\begin{tabular}{|c|c|c|c|}
\hline Panse & $\begin{array}{c}\text { R.-A. } \\
\mathrm{cm}\end{array}$ & Einstellung & nach Schluss \\
\hline je 1 Minute & $\begin{array}{l}7,5 \\
5,75\end{array}$ & $\begin{array}{l}8,1 \\
7,2\end{array}$ & $\begin{array}{l}8,7 \\
7,2\end{array}$ \\
\hline
\end{tabular}

Kokain von 2,5\% wird in oben angegebener Weise auf das Cerebralgangl. aufgepinselt. je 1 Minute

$$
\begin{aligned}
& \begin{array}{|l|l|l|l|l}
5,5 & 8 & 11 & \begin{array}{c}
\text { Physikalisch-chemische Wir- } \\
\text { kung vor dem Eindringen. }
\end{array} \\
5,5 & 7 & 7,1 & \text { Zunehmende Lähmung } \\
5,5 & 6,5 & 6,5 & \\
5 & 6,5 & 6,5 & \\
4,5 & 6,2 & 6,5 &
\end{array} \\
& \text { Kokainkristall auf das Cerebralganglion } \\
& \begin{array}{|l|c|c|c}
4,5 & 10 & 13 & \text { Vollkommene Lähmung } \\
5 & 6,5 & 7 &
\end{array}
\end{aligned}
$$


Das Cerebralganglion kann am Schlusse dieses Versuches mit der Pinzette zerquetscht werden, ohne dass der Muskel reagiert.

Der gleiche Versuch unter Prüfung der „Reflexerregbarkeit" (Ausschlagshöhe) durch Einzelschläge gibt folgendes Resultat:

Tabelle 32.

Normales Tier mit $15 \mathrm{~g}$ belastet. Reflexerregbarkeit durcb Einzelschläge.

\begin{tabular}{c|c|c}
\hline \hline Zeit & Einstellung & nach Schluss \\
\hline 12 h 28, & 6,2 & 11 \\
12 h 30', & 6,1 & 11,3 \\
12 h $32^{\prime}$ & 5,9 & 9,4
\end{tabular}

Kokain 2,5\% auf das Cerebralganglion

\begin{tabular}{l|l|l}
$12 \mathrm{~h} 36^{\prime}$ & 6,8 & 8,1 \\
$12^{\mathrm{h}} 38^{\prime}$ & 5,3 & 6,9
\end{tabular}

Exstirpation des Cerebralganglion

12 h $42, \quad$ | $6,8 \quad \mid 10$

Beide Versuchsanordnungen zusammen wurden elfmal mit gleichem Hauptresultate wiederholt.

Dieses Hauptresultat aber lautet: Wenn Kokain in mässiger Konzentration und mäsiger Dose in das Cerebralganglion eindringt, so bedingt das eine Herabsetzung der Erregbarkeit sowie der Arbeitsleistung auf konstanten Reiz hin.

Auf die technischen Schwierigkeiten, die dieser Versuch bietet, habe ich schou teilweise bei Darstellung der analogen Experimente am Pedalganglion hingewiesen. Wir begegnen hier wiederum den nämlichen individuellen Verschiedenheiten der Geschwindigkeit der Wirkungsentfaltung von seiten des Kokains. Dergestalt lässt sich niemals die erste Reaktion nach der Vergiftung vorbersagen; an der Reaktion selbst aber können wir unmittelbar feststellen, mit welcher Phase wir es zu tun haben. 1. Häufig, hesonders wenn man unmittelbar nach Aufpinselung reizt, erhält man gesteigerten Ausschlag. Dabei reagiert der Muskel auf Berübrung des Cerebralganglion sehr lebhaft. Ich werde zeigen, dass wir es hier mit einer erregenden Wirkung (noch vor Eindringen des Kokains) zu tun haben, die mit jeder beliebigen anisotonischen Lösung zu erreichen ist. Schon der zweite Schlag zeigt Abfall der Erregbarkeit. 2. Wenn man nicht unmittelbar reizt, so erhält man, da dann das Kokain schon ein- 
gedrungen ist, sofort Abfall der Frregbarkeit (zweiter Versuch). 3. Wartet man zu lange, oder bedient man sich zu grosser Konzentration, so erhält man unmittelbar gesteigerte Erregbarkeit, die jedoch einmal keinem Abfalle Platz macht, dann aber auch durch Unerregbarkeit des Cerebralganglion sich als durch dessen Lähmung verursacht dokumentiert.

B) Aufpinselung von Kochsalzlösungen auf das Cerebralganglion. Diese Versuche wurden in zweifacher Absicht angestellt: Erstens musste ich mir sagen, dass, wenn Kokain vorab erregungssteigernd wirkt, wir diese Wirkung aber durch Anisotonie erklären wollen, jede andere anisotone Lösung die nämliche Reaktion hervorrufen müsste. Ferner aber dürfen wir Kochsalzlösungen sozusagen als Gegensatz zu Kokainlösungen betrachten, da ihre erregende Wirkung auf andere nervöse Elemente ja bekannt ist. Ich teile nur die mit $\mathrm{NaCl}$ gewonnenen Resultate mit, an deren Stelle solche mit Rohrzucker usw. hätten treten können.

\section{Tabelle 33.}

Normales Tier. Direkte Reizung durch Wechselstrom.

\begin{tabular}{c|c|c}
\hline $\begin{array}{c}\text { R.-A. } \\
\mathrm{cm}\end{array}$ & Einsteljung & nach Schluss \\
\hline 5,25 & $\begin{array}{l}3,5 \\
4\end{array}$ & $\begin{array}{c}4 \\
5,5\end{array}$ \\
\hline
\end{tabular}

Nun wird NaCl-Lösung zu $3 \%$ anf das Cerebralganglion aufgepinselt, ein Eingriff, auf den der Muskel durch Kontraktion reagiert; man wartet, bis jegliche sichtbare Erregung abgelaufen ist, und reizt dann ${ }^{1}$ ).

\begin{tabular}{c|c|c}
\hline $\begin{array}{c}\text { R.-A. } \\
\mathrm{cm}\end{array}$ & Einstellung & nach Schluss \\
\hline \begin{tabular}{c|c}
5,25 \\
5,5
\end{tabular} & $\begin{array}{l}3,5 \\
2,3\end{array}$ & $\begin{array}{l}6 \\
2,3\end{array}$
\end{tabular}

Ein NaCl-Kristall auf das Cerebralganglion

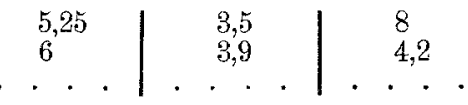

1) Reagiert der Muskel auf die Bepinselung nicht, so überzeuge man sich, ob das Cerebralganglion mit dem Tiere noch in funktionellem Znsammenhange steht; dieser kann während der Präparation leicht gestört worden sein. 
Die gleiche Versuchsgattung habe ich mit "Reflexerregung" angestellt, und zwar ausnahmsweise auch durch Wechselströme und unter Messung des Rollenabstandes. Da es nun aber zur „Reflexerregung" stärkerer Ströme bedarf als zur "direkten" Erregung, so mussten die Rollen etwas übereinandergreifen, so dass die Zahlen die Abstände des inneren Randes der Sekundär- vom inneren Rande der Primärrolle bedeuten ( $\left(R_{.}-A_{1}.\right)$, also diejenigen Abstände angeben, die man gewöhnlich zu messen pflegt. Dies nur nebenbei, da dergleichen bei der Vergleichung keine Rolle spielt.

Tabelle 34.

Normales Tier. "Reflexerregung" durch Wechselströme.

\begin{tabular}{c|c|c}
\hline $\begin{array}{c}\text { R.-A } \\
\mathrm{cm}\end{array}$ & Einstellung & nach Schluss \\
\hline 8,5 & 5,7 & 5,7 \\
8,25 & 5,1 & 6 \\
\multicolumn{2}{c|}{$\mathrm{NaCl}$ auf das Cerebralganglion } \\
8,25 & 5,4 & 6,9 \\
8,5 & 5 & 5,8 \\
$\ldots, \% 5$ & $\ldots, 2$ & 4,5
\end{tabular}

Neues NaCl-Kristall auf das Cerebralganglion

\begin{tabular}{l|r|r}
8,75 & 5,5 & 5,8 \\
8,75 & 10,0 & 15,0
\end{tabular}

Es wird also Erregbarkeit und Arbeitsleistung (vgl. beide Proto. kolle) wesentlich gesteigert, wenn das Cerebralganglion durch Aufpinseln von Kochsalzlösungen oder Auflegen von Kochsalzkristallen in einen Erregungszustand versetzt wird. Dass nämlich hier keine Ausschaltung der Funktion vorliegt, lässt sich leicht zeigen: Je grösser die Kochsalzwirkung, um so grösser die direkte Erregbarkeit des Cerebralganglion.

Es handelt sich in dem Mitgeteilten auch nicht etwa um eine Reizsummation einfachster Art, dergestalt, dass etwa das Kochsalz das Cerebralganglion reize, jedoch nicht stark genug, dass ein Effekt zustande käme, aber wohl stark genug, um meinen künstlichen elektrischen Reiz zu unterstützen. Denn dann müssten wir auch am Pedalganglion die gleiche Erscheinung beobachten können. In Wirklichkeit erzielen wir das Gegenteil. Das ist nun auch nicht so zu verstehen, dass an jenem Unterschiede nu r der hohe Kontraktionszustand nach Beeinflussung des Pedalganglion schuld sei, so dass - erzielten wir 
nur den gleichen Zustand bei Einwirkung auf das Cerebralganglion die Erregbarkeit auch vermindert würde. Man braucht, um das zu zeigen, ja nur eine der vielen gelegentlichen "Schwankungen" abzuwarten, z. B.:

R.- $A_{1}$ Einstellung nach Schluss

$8,25 \quad 6 \quad 6$

$\mathrm{NaCl}$ auf das Cerebralganglion

$8,25 \quad 14 \quad 15$

Es bleibt die Frage zu entscheiden, ob das Cerebralganglion im erregten Zustande seine Hemmung lediglich reduziert, oder ob es sogar imstande ist, über den Nullpunkt dieser Hemmung hinauszugehen, d. h. die an sich grosse Erregbarkeit des Systems I. Ordnung noch zu steigern.

Tabelle 35.

Je ein normales Tier; direkte Erregung durch Wechselströme.

1.

\begin{tabular}{|c|c|c|c|c|c|}
\hline $\begin{array}{c}\text { R.-A. } \\
\mathrm{cm}\end{array}$ & Einstellung & nach Schluss & $\begin{array}{c}\text { R.-A. } \\
\text { cm }\end{array}$ & Einstellung & nach Schluss \\
\hline $\begin{array}{c}5,25 \\
\mathrm{NaCl}\end{array}$ & $\begin{array}{c}10 \\
\text { f das Cerelur }\end{array}$ & $\begin{array}{c}10 \\
\text { lganglion }\end{array}$ & $\frac{2,5}{3}$ & $\begin{array}{r}10,5 \\
8,2\end{array}$ & 12 \\
\hline $\begin{array}{l}5,25 \\
5,5 \\
5,5 \\
\\
\text { Exstir }\end{array}$ & $\begin{array}{c}11,5 \\
8,6 \\
8 \\
\\
\text { des Cerel }\end{array}$ & $\begin{array}{c}17 \\
9,1 \\
8,9 \\
\text { ralganglion }\end{array}$ & $\begin{array}{l}\mathrm{NaCl} \\
3 \\
3,75 \\
4\end{array}$ & $\begin{array}{l}\text { f das Cerebra } \\
10,5 \\
7 \\
7\end{array}$ & $\begin{array}{c}\text { lganglion } \\
15 \\
7,5 \\
7\end{array}$ \\
\hline $\begin{array}{l}5,5 \\
5\end{array}$ & $\begin{array}{c}9,4 \\
10\end{array}$ & $\begin{array}{c}9,4 \\
11\end{array}$ & \multicolumn{3}{|c|}{$\begin{array}{l}\text { Exstirpation des Cerebralganglion. Erreg- } \\
\text { barkeit erst bei R.-A. } 3,5 \text { nachweisbar. }\end{array}$} \\
\hline
\end{tabular}

Wir schliessen also aus allen diesen Versuchen das Folgende: Wen wir das Cerebralganglion durch eine anisotonisehe NaCl-Lösung (oder durch Kochsalzkristalle) in eine Art von Erregungsustand versetzen, die uns ihrem Wesen nach unbekannt ist, jedoch an sich eine Kontraktion des Muskels nicht bedingt, so steigt die Erregbarkeit der Muskulatur auf reflektorische und Bahnenreizung. Kurz, das Tier würde sich verhalten wie ein cerebralloses, wäre nicht gerade unter diesen Bedingungen die Funktionstüchtigkeit des Cerebralganglion durch dessen direkte Reizung besonders leicht nachweisbar, und würde nicht - gleichfalls unter diesen Bedingungen - auf Exstirpation des Cere- 
bralganglion und im Gegensatz zur Norm die Erregbarkeit (etwas) fallen. Auch diese Funktion des Systems I. Ordnung, die Erregbarkeit, kann dureh das ihr übergeordnete Ganglion nicht ausschliesslich gehemmt, sondern auch gelegentlich gesteigert werden.

\section{II. "Ökonomische" Betrachtungsweise der Ergebnisse").}

Mit der vorliegenden zweiten Untersuchungsreihe glaube ich die notwendigsten eigentlichen Vorarbeiten zu einer Untersuchung über Mechanik und Regulierung der Lokomotion bei Pulmonaten abschliessen zu können. Ich möchte mir hier erlauben, durch eine, wenn auch vielleicht noch in mancher Beziehung verfrühte Synthese eine Art Perspektive dessen zu geben, was wir mit dem Materiale späterhin zu erreichen boffen. Was die Regulierung des tonischen Zustandes anbetrifft, so muss ich natürlich auf Mitteilung I verweisen.

\section{A. Das Problem der normalen Lokomotion.}

Zur Erklärung der normalen Lokomotion hatten wir zwei Möglichkeiten unterschieden: Entweder, sagten wir, muss ein komplizierter Reflexapparat vorhanden sein, oder die Wellen werden, auf Grund der uns teilweise bekannten Gesetze des Tonus und der Erregbarkeit, hervorgerufen durch einen einfachen kontinuierlichen, reflektorischen Erregungsvorgang.

Den komplizierten Reflexmechanismus nimmt Biedermann in seiner neuesten Arbeit über Schneckenlokomotion an ${ }^{2}$ ). Dieser Forscher bestätigt und erweitert meine Beobachtung, dass eine ganglienlose Aplysia zur Lokomotion nicht mehr imstande sei, an Helix. Auch kleinere Muskelpartien, soweit sie nur durch Zerschneidung der zugehörigen Bahn vom Pedalganglion getrennt sind, werden aus dem Gesamtspiel der Lokomotion ausgeschaltet; daran ändert das Intaktsein des Nervennetzes nichts, wie auch umgekehrt das Nervennetz vollständig durchschnitten sein kann, ohne dass -

1) Da ich eine Zusammenfassung am Schlusse nicht gebe, so sei darauf hingewiesen, dass dieser Teil alle wichtigeren Tatsachen, die in Teil I gefunden wurden, anführt.

2) W. Biedermann, Studien zur vergleichenden Physiologie der peristaltischen Bewegungen. II. Die lokomotorischen Wellen der Schneckensohle. Pflüger's Arch. Bd. 107 S. 1-56. 
sind nur die Bahnen erhalten - die Peristaltik eine Abweichung von der Norm aufwiese.

Darf man aus diesem Befunde schliessen (wie ich es seinerzeit für Aplysia tat), dass das Pedalganglion das Lokomotionszentrum ist? Ich glaube nicht. Ein naturwissensehaftlicher Beweis gilt dann als erbracht, wenn jede andere Erklärung, als die zu beweisende, soweit wir nämlich eine solche auszudenken imstande sind, durch die gefundenen Tatsachen ausgeschlossen werden kann. Dies aber ist für den vorliegenden Fall nicht möglich. Wir wissen, dass der einfache Reflex sowohl durch das Netz gehen als den Weg über das Pedalganglion wählen kann, denn das zeigen in unzweideutiger Weise unsere Versuche über die Reflexerregbarkeit von Tieren mit und ohne Pedalganglien. Wenn es uns gelingt, nachzuweisen, dass die Lokomotion auf Grund eines derartigen einfachen Reflexes zustande kommt, dann bedürfen wir der Annahme eines "Lokomotionszentrums" im Pedalganglion gar nicht, um zu verstehen, warum dieses Ganglion zur Lokomotion notwendig sei: es genügt die Voraussetzung, dass der Leitungswiderstand im Netz für die lokomotorische Erregung eine zu grosse sei - eine Voraussetzung, die durch Tatsachen wohl gestützt ist. Oder: Die Tonusregulierung von seiten des Pedalganglion ist für das Zustandekommen der Lokomotion eine Notwendigkeit, ein Verhalten, welches lediglich das Recht geben würde, im Pedalganglion den Beherrscher des Tonus zu sehen. Dass dies aber wahr sei, daran ist sowieso kein Zweifel möglich. (Die letztere Annahme würde übrigens an sich sehr gut mit dem Vorhandensein eines lokomotorischen Reflexmechanismus in Einklang zu bringen sein.)

Ist der Beweis, dass das Pedalganglion als Lokomotionszentrum anzusehen sei, dergestalt nicht zu erbringen, so lassen sich gegen diese Annahme, wie mir scheint, gewichtige Gründe geltend machen: der Gattung Helix nahe verwandte Formen bedürfen nämlich zu einer qualitativ durchaus normalen Lokomotion der Ganglien in keiner Weise. Von den Versuchen Künkel's an Limax habe ich in Mitteilung I gesprochen und auch angegeben, dass ich sie mit positivem Resultate nachgeprüft habe. Etwas Leichteres als diese Nachprüfung lässt sich gar nicht denken. Nun überlege man folgendes: Der Bau des Nervensystems bei Limax ist im Prinzip durchaus gleich demjenigen bei Helix. Trotzdem findet sich ein komplizierter Reflexmechanismus bei Limax einerseits im Nervennetz, und zwar 
diffus lokalisiert (das kleinste Stück mit dem Rasiermesser herausgeschnittener Fussmuskelsubstanz mit Epithel führt normale Wellen aus); dieser selbe komplizierte Reflex hat bei Helix andrerseits sein Zentrum im Pedalganglion. Ein solch komplizierter Reflex, bei dem stattgehabte Kontraktion nicht nur auf Grund rätselhafter Einrichtungen kirschlaffung bedingt, sondern bei dem in gleichfalls unbekannter Weise die Erregung in ibrem Doppelspiele von Bahn zu Bahn, von hinten nach vorn wandert, eine solche Einrichtung ist einem komplizierten Organe zu vergleichen; wer aber die Trägheit phylogenetischer Umgestaltung und die Zähigkeit kennt, mit der die Natur an den einmal erzielten Organen festhält, diese lieber verändernd als sie ausgemerzt durch neue zu ersetzen, der wird meinen Zweifel teilen, daran nämlich, dass das Organ bei Limax im Netz, bei Helix aber im Ganglion zu suchen sei. Mit anderen Worten: Der Beweis, dass das Pedalganglion das Lokomotionszentrum sei, ist bislang nicht nur nicht zu erbringen, sondern es sprechen auch gewichtige Gründe gegen diese Annahme. Wir werden uns in einer späteren Vitteilung mit dieser Frage zu beschäftigen haben.

Wenden wir uns nunmehr zu jenem „komplizierten Reflexe", wie ihn Biedermann für die Lokomotion verantwortlich macht. Eine derartige Annahme verlangt als conditio sine qua non ibrer Berechtigung den Nachweis von Nerven, deren Erregung die Muskulatur unmittelbar zur Erschlaffung bringt, also von „Hemmungsnerven“. Diesen Nachweis zu erbringen, hat sich Biedermann bemüht (l. c. Nr. II S. 48-50). Er reizt die vom Pedalganglion ausgehenden und von ihm abgetrennten Bahnen durch Wechselströme. Da die Pedalganglien entfernt worden sind, so befindet sich die Muskulatur im Zustande gesteigerten Tonus. Dadurch aber erscheint der hintere Abschnitt des Tieres „ganz geschrumpft, trocken, glanzlos und von bräunlicher Farbe". Lässt er nun das Induktorium spielen, so sieht er das bekannte Wechselspiel zwischen Kontraktion und Erschlaffung. „Das, was aber die Aufmerksamkeit am meisten bei einem solchen Versuche fesselt, ist die während der Reizung sichtlich fortschreitende Schwellung und Glättung der ursprünglich so stark geschrumpften und gerunzelten Muskelmasse."

Auch in weiteren Versuchen bestätigt sich diese "primäre Erschlaffung" auf Bahnenreiz, dem Augenscheine nach.

Ich hoffe, mein verehrter Lehrer wird es mir nicht verübeln, 
wenn ich ihm bezüglich der Deutung seiner Befunde entgegentrete: Was beweisen obige Versuche? Dass die Oberfläche des Tieres, die runzlig war, anschwillt und glatt wird. Wodurch kann das bedingt werden?

1. Durch Muskelerschlaffung: dann nämlich, wenn das Lakunensystem im Muskel- und Bindegewebe über eine grosse Quantität von Wasser verfügt. Dann sieht aber vor der Erschlaffung und in Tonus die Oberfläche nicht ,ganz geschrumpft, trocken, glanzlos und von bräunlichgelber Farbe" aus, sondern die zieriichen Felder der Rückenoberfläche erscheinen als mehr oder weniger deutliche Blasen abgesetzt turgeszent glänzend, durch den Wassergehalt hellgefärbt. In diesem Falle kann man weit eher von kleinblasigem als von runzligem Aussehen reden. Man lege eine Helix stundenlang in Wasser, bis sie aufquillt, und reize sie (ohne den Körper zu eröfnen), so wird man sich von dem Gesagten überzeugen. Bringt man ein solches (oder auch ein normal vollsaftiges) Tier etwa durch Alkaloide zur Erschlaffung, dann, aber auch nur dann, tritt Glättung ein, den Vorgang selbst habe ich in meiner Arbeit über Aplysia beschrieben.

Ein runzliges, trocken aussehendes Tier wird in der Regel dem Auge seine Erschlaffung gar nicht oder kaum dokumentieren (das Zusammensinken des Helixkörpers ist nur eben wahrnehmbar), da gar kein Agens vorhanden ist, die Muskulatur auszudehnen.

2. Die Glättung der Oberfläche einer Schnecke kann erfolgen durch Muskelkontraktion, dann etwa, wenn die Kontraktion keine allgemeine, sondern eine partielle ist, dergestalt, dass Blut aus den kontrahierten in nicht kontrahierte Partien gepresst wird. Man lege doch ein Tier in Wasser und beobachte seine Lokozotionswellen, nachdem es reichlich Wasser aufgenommen hat. Die helle Zone (Dehnungszone) der Welle ist hell, nicht weil hier das Muskelplasma nicht geronnen ist, sondern weil der Hauptteil des betrachteten Substanzvolumens an dieser Stelle eine Wasserwelle ist. Dieses Wasser kommt hierhin nicht durch Erschlaffung, da diese an sich nur eine runzlige Oberfläche bedingen würde, sondern lediglich durch die Kontraktion der Nachbarteile. In diesem Falle, und bei Helix in den meisten Fällen überhaupt, wird die Glättung durch Kontraktion benachbarter, oder nach innen gelegener Muskelteile bedingt. In den von Biedermann beschriebenen Fällen war der Fuss "maximal" kontrahiert. Unter diesen Umständen bedingt nach 
meiner Erfahrung ein schwacher Reiz immer noch eine Kontraktion, aber sehr geringen Grades, jedoch eben genügend, um den Rest Blut unter das Epithel zu drücken.

Ich gebe zu, mit derartiger Deduktion beweise ich nicht, dass es keine Hemmungsnerven gibt; aber, bleiben wir unserer Beweismethode treu:

1. zu zeigen, dass die zu widerlegende Behauptung nicht die einzige sei, die mit den Tatsachen in Einklang zu bringen ist um so besser, wenn wir sie selbst zugleich unwahrscheinlich machen können;

2. Tatsachen zu erbringen, mit denen die zu widerlegende Behauptung sich nicht oder doch schwer in Einklang bringen lässt. Darf ich mich somit zum zweiten Teile der Beweisführung wenden, nachdem der erste mir gelungen zu sein scheint:

1. Fine Erschlaffung ohne Belastung dokumentiert sich gar nicht; daher müssen wir, wenn wir ja Erschlaffung nachweisen wollen, den Muskel, wenn auch schwach, belasten, warten, bis absolute "Konstanz" eingetreten ist, und dann mit allen möglichen Intensitäten sowohl Ganglien als Bahnen reizen. Zeigt in allen Fällen der Zeiger entweder gar nichts, oder aber Steigerung (je nach Reizintensität), so gibt es keine "Hemmungsnerven".

Ich habe nun Cerebralganglion, Pedalganglien und Bahnen (letztere mit und ohne Ganglien) von einer grossen Anzahl Schnecken, unter höherer und geringerer Belastung, mit Rollenabständen von $2,5 \mathrm{zu}$ $2,5 \mathrm{~mm}$ unter obigen Bedingungen gereizt und kannmit aller Bestimmtheit sagen, dass es nureine Alternative gibt: Nichts oder Kontraktion, je nach Rollenabstand.

2. Diese Versuche habe ich, wenn anch nicht mit Hilfe eines objektive Werte gebenden Apparates, schon an Aplysia ausgeführt. Dieses Tier ist stets wasserreich und bereitet dem Beobachter daher nicht die Täuschung, der man - wie oben gesagt - bei Helix ausgesetzt ist. Ich habe trotzdem in Mitteilung I das Vorhandensein von Hemmungsnerven nicht als ausgeschlossen hingestellt, weil ich nicht gern behaupte, solange mir noch ein Einwand als möglich erscheint. Ich bin heute in der Lage, die Negierung von Hemmungsnerven durch ein weiteres wesentliches Argument zu stützen.

Jener Einwand, den ich nämlich gegen die Negierung zuliess, war folgender: Es wäre möglich, dass die Bahnen derartig aus er- 
regenden und hemmenden Fasern gemischt verliefen, dass die summierte Wirkung bei gemeinsamer Reizung Kontraktion sei. Als Anhänger der Lehre von den Hemmungsnerven (bei der Schnecke) würde ich diesen Einwand nicht wagen, da, wie wir stets saben, die hemmende und nicht die erregende Wirkung der Ganglien vorherrscht, und andrerseits notorische Hemmungsnerven durch Wechselströme ebensogut in Tätigkeit gesetzt werden als andere. Wie dem auch sei, obigen Einwand kann man gleichfalls hinfällig machen :

Wir wissen, dass partielle Lähmung des Pedalganglion den Tonus zum Fallen bringt. Es handelt sich hierbei durchaus nicht um eine erregende Vorphase der Kokainwirkung auf ein „Hemmungszentrum", da Kochsalz und Analoga den Tonus stets steigern. Wenn nun das Pedalganglion den Tonus dauernd herabsetzt, partiell geJähmt dies aber noch mehr tut, so habe ich -- will ich überhaupt bei der Vorstellung von Hemmungsnerven bleiben - nur eine Möglichkeit: Das Kokain wirkt auf das hemmende System, verglichen mit dem erregenden, in geringerem Masse, oder es wirkt gar nicht; denn wirkte es gleichförmig, so würde die in der Norm prädominierende Funktion durch das Gift am meisten beeinträchtigt werden: der Tonus würde steigen. Wenn ich nun gesagt habe: Reizung des Pedalganglion (oder des Cerebralganglion oder der Bahnen) bedingt nur darum keinen Tonusfall, weil die erregenden Fasern überwiegen und daher stärker gereizt werden, so habe ich doch jetzt die Bedingung geschaffen, unter derdas nicht affizierte hemmende, über das ganz oder doch teilweise gelähmte erregende System siegt. Ja, wenn ich weiter vergifte, $\mathrm{muss}$ der Punkt erreicht werden, an dem nur mehr hemmende Fasern erregbar sind. Wenn es also überhaupt hemmende Fasern gibt, so muss bei Reizung des kokainisierten Pedalganglion Tonusfall in der Muskulatur eintreten. Das Resultat aber ist: Nichts oder Kontraktion, je nach Intensität der Reiz-oder Giftwirkung, die beide nach Kräften variiert wurden.

Die nämlichen Verhältnisse bestehen für das Cerebralganglion mit analogem Versuchsresultat: Jede Reizung, ob mit oder ohne Kokain, bedingt Kontrakti on oder nichts; dabei ist die Funktion dieses Ganglion dauernde Hemmung der Erregbarkeit und der Reflexe. Ich habe mich bemüht, objektiv zu sein, d. h. alle Einwände gegen 
meine Beweisführung nicht nur anzuerkennen, sondern selbst aufzusuchen. Ich bin jetzt am Ende! Solange mir nicht gezeigt wird, dass meine Beweisführung in allen wesentlichen Teilen falsch ist, und zwar unter Berücksichtigung aller Tatsachen und Argumente, muss ich sagen: Es gibt im lokomotorischen System der Schnecke Keine Nervenfasern, die auf Erregung einen Fall des Tonus oder eine Erschlaffung der Muskulatur bewirken.

Kommen wir nunmebr auf die Lokomotion zurück. Ich glaube sagen zu können, dass wir diese Frage auf einige wenige Probleme reduziert haben. Das erste Problem ist das von Biedermann 1. c. II S. 51 teilweise formulierte: Trotz Unabhängigkeit der Wellen von der Form des Nervennetzes ist ihr Auftreten an Erregungsbezirke gebunien. Wodurch wird dies Verhalten bedingt, und ist hierdurch das erste Auftreten einer Kontraktion an einem zirkumskripten Teile der Muskulatur zu erklären? Lösung dieses Problems heisst Beantwortung der Frage nach dem Rhythmus überhaupt. Denn wir haben ja gesehen, dass, wenn durch Kontraktion eines solchen Teiles, durch den hierdurch bedingten Blutdruck ein Nachbarteil gedehnt wird, dieser nun das Übergewicht erhält, so dass er durch seine eigene Kontraktion den ersten Teil zu dehnen vermag, usw. Das sind Tatsachen. (Vergl. auch v. Uexküll's Versuch.)

Das zweite Problem ist die Richtung der Peristaltik. Mit dieser Frage haben wir uns in vorliegender Mitteilung noch gar nicht beschäftigt.

\section{B. Die Reguliernng der Reflexe und der Lokomotion durch das Zentralnervensystem.}

Die in Abschnitt I mitgeteilten Tatsachen haben wir also vorläufig zur Erklärung der normalen Lokomotion d efin iti v nicht verwertet, uns dies vielmehr für eine' spätere Untersuchung aufgespart. Hingegen liessen uns eben diese Versuche Einblick gewinnen in einen Teil derjenigen Mechanik, welche die Regulierung der Bewegungen bedingt.

Wir haben gesehen, dass die Schnecke über zwei Zentrensysteme verfügt, die beide nicht nur als Knotenpunkte einer Kommunikation, sondern als Regulationsapparate der gesamten Muskelleistung dienen. Das Cerebralganglion beherrscht zum grossen Teil die Reizschwelle und die Arbeitsleistung der Muskulatur, und zwar, wie es scheint, in ganz unmittelbarer Weise. Diese Regulierung ermöglicht dem 
Tiere sogar, trotz gewisser, nicht eben maximaler äusserer Eingriffe, seine Bewegung auf die Norm zu beschränken. Der Grad dieser Leistung dürfte eine Anpassung an äussere Bedingungen sein, also z. B. an diejenigen Temperaturen, die in unserem Klima als Maximum aufzutreten pflegen.

Die Pedalganglien beherrschen in unmittelbarer Weise nur den tonischen Zustand der Muskulatur, daher nur mittelbar Reizschwelle und Leistung. Wir haben keinen Grund, anzunehmen, dass diese mittelbare Leistung der Pedalganglien für gewöhnlich über folgendes hinausginge: Der normale Ablauf der Bewegung bedarf einer sorgfältigen Regulierung des Tonus, die eben die Pedalganglien besorgen. Erst inverhalb dieser Grundbedingung entwickeln sich die feineren Abstufungen der Bewegung, Abstufungen, die ibrerseits lediglich ein Produkt des Cerebralganglion sind. Und zwar haben wir uns seine Leistungen folgendermassen vorzustellen: Das System I. Ordnung (Rezeptoren, Nervennetz, Effektoren) vermag alles Notwendige zu leisten, aber in übertriebener Weise. Die Regulierung geschieht durch mehr oder weniger ausgiebige "Hemmung" (nicht im landläufigen Sinne, durch "Hemmungsnerven“), an deren Stelle nur gelegentlich Steigerung tritt, wobei es fraglich bleibt, ob innerhalb des Lebens der Schnecke hierzu je die Bedingungen gegeben sind. Kurz, wir erhalten vollkommene Analogie in der Funktionsweise der beiden Zentren, Cerebral- und Pedalganglien, mit ihren - an sich grundverschiedenen Leistungen. "Hemmungszestren" sind sie beide nicht, so wenig ein Reiter auf einem feurigen Pferde nur fürs Zurückhalten da ist.

Was bedingt nun inmerhalb des Lebens einer Schnecke das Einsetzen solcher Regulierung? Ich will bemerken, dass das Folgende noch der Gegenstand experimenteller Untersuchung sein wird, die ich mir vorbehalte. Was ich hier gebe, ist im wesentlichen, wie oben angedeutet, eine Perspektive. Wir haben gesehen, die Regulierung geschieht je nach Zustand der Ganglien: Eine Schnecke (Aplysia) ohne Cerebralganglion bewegt sich stets, mit Cerebralganglion wenig. Diese Hemmung ihrerseits findet jedoch nur statt, solange der aktive Zustand des Ganglion ein geringer ist. Je mehr dieser jedoch steigt, desto mehr nimmt das Tier den Habitus eines Cerebrallosen an, wie wir sahen: das Tier setzt sich ebenfalls in Bewegung. Es steigt aber dieser aktive Zustand höchstwahrscheinlich durch Erregung der Hauptsinnesnerven. 
Ich bitte diese Tatsachen nicht zu unterschätzen: Über die Bedeutung der Hauptsinnesapparate als Auslöser von Reflexen ist man sich stets einig gewesen. Hier handelt es sich aber unmittelbar gar nicht um Reflexe! Denn solche spielen sich innerbalb des Systems I. Ordnung ab und berübren das Cerebralganglion insofern nicht, als dieses, ja das ganze Gangliensystem entfernt werden kann, ohne dass die Reflexe qualitativ verändert würden. Gewiss, es ist nichts Neues, dass Entfernung eines Oberzentrums die Funktionen des niederen begünstigt, dass „am sichersten und regelmässigsten ein Zentrum eine bestimmte Reflexfunktion erfüllt, wenn aller Zusammenhang desselben mit anderen Zentren aufgehoben wird." (Goltz zitiert nach Bi e dermann l. c. I S. 537.) Denn - sagt man - die Funktion des Reflexzentrums wird gestört durch die Erregung von seiten eines am Reflexe unbeteiligten zweiten Zentrums. "Hemmung ist auch Erregung, aber eine, andere Erregungen störende Erregung." (H. E. Hering, Erg. Physiol. I Jahrg. 2 S. 516, zitiert nach Biedermann I S. 537.)

Aber darum handelt es sich hier ja gar nicht! Erregung von seiten eines am Reflexe unbeteiligten Ganglion s teigert gerade den Reflex, Entfernung aber auch. Gemindert wird der Reflex aber durch Beseitigung der Erregung in ebendiesem Zentrum. Gerade dass das Zentrum auf Erregung den Reflex, den es nicht erzeugt, steigert, gerade dass es ohne Erregung, ohne "aktiven Zustand" den Reflex am Funktionieren hindert, macht die ganze Einrichtung zu einer ökonomisch so überaus zweckmässigen! Aber nicht nur in ökonomischer, auch in kausaler Beziehung ist dieses Verhalten interessant, wie wir sehen werden. Dass wir es nicht mit einer Summierung von Reizen zu tun haben, einem zu schwachen Reflex im System I. Ordnung plus einer zu schwachen Erregung des Cerebralganglion, die gemeinsam eine Muskelkontraktion oder Lolomotion bedingen, das habe ich schon gezeigt ${ }^{1}$ ): Das Pedalganglion ist viel rezeptiver für direkte Erregung, als das Cerebralganglion, und doch bedingt seine Behandlung mit entsprechenden Substanzen gegensätzliches Verhalten. Dass hieran ein mehr oder weniger boher Kontraktionszustand des Muskels nicht schuld ist, habe ich dargetan.

Man bat eine Zeitlang geglaubt, etwas erreicht $z u$ haben, wenn

1) Hingegen erscheint es mir nicht ausgeschlossen, dass dasjenige, was man "Reizsummation" genannt hat, auf obige Erscheinung zurückzufuhren ist. 
man zeigte eine reflexähnliche Reaktion sei ein Tropismus. Später, als man sah, dass es sich gar nicht um „elementare Funktionen des Plasma" handelte (die ohnebin nicht weniger rätselhaft sein würden), musste die Fragestellung sich umdrehen: Die meisten Tropismen mussten auf Reflexe zurückgeführt werden. Aber wie ist das möglich? Der Lokomotionsreflex kreist in den unteren Zentren, die Tropismen aber sind an die Sinuesnerven gebunden, in denen wohl eine einmalige Differenz der Erregungsintensität einen einmaligen Reflex erzeugen kann, von denen aber gar nicht einzusehen ist, wie sie unter dem Einflusse dauernder schwacher Erregung Reflexe quantitativ zu beeinflussen vermögen, die sie an sich hervorzubringen gar nicht imstande wären. Hier scheint mir der Weg gegeben, wenigstens für unser Objekt und analog organisierte Wesen, dieses Rätsel zu lösen: Ein Tier, dessen Cerebralganglion etwa durch Licht erregt wird, wird sich verhalten, als babe es Kochsalzlösung auf diesem Zentrum: Der stets vorhandene Reiz wird nun, und $z$ war n u n erst nach Belichtung - genügen, um das System I. Ordnung zur Lokomotion zu veranlassen. Dann ist zweierlei möglich: Entweder es genügt für diese Erscheinung diffuses Licht, dann wird das Tier. erst zur Ruhe kommen wenn es den Schatten erreicht hat, und dann nennen wir das Tier negativ phototropisch; uder es ist direkte Belichtung nötig, dann wird das Tier nur kriechen, wenn es seine Photorezeptoren dem Lichte zugekehrt hat, es wird dem Lichte zukriechen: „positiver Phototropismus“. Anch Kreisbewegungen nach einseitjger Blendung siıd nach obigem "erklärbar".

Nun, das sind natürlich Spekulationen, die jene Probleme in keiner Weise als gelöst hinstellen sollen. In Gegenteil, sie genügen bei weitem nicht, um auch nur hypothetisch alle in Betracht kommenden Erseheinungen zu erklären. Aber ich bin überzeugt, dass wir an der Hand obiger Tatsachen ernstlichen Schwierigkeiten bei solchen Interpretationen nicht mehr begegnen werden: Jedes Ticr ist ein Anpassungsprodukt an unzählig variierte äussere Bedingungen. Der Grundgesetze sind nicht viele, um so zahlreicher ihre Abänderungen, eben auf Grund der Anpassung; für uns also etwa je nach Reizschwellen und anatomischer Anordnung der Bahnen. Der Weg ist gegeben, und ich hoffe selbst ihn betreten zu köinnen. 
C. Anwendung der Versnchsergebnisse anf einige Tatsachen, die an sich nicht Gegenstand dieser Untersuchnng waren.

In gleicher Weise, wie ich es für die Tropismen getan, will ich versuchen einige andere Erseheinungen hypothetisch mit den obigen Ergebnissen in Verbindung zu bringen. Ich will so wenig als bei den Tropismen eine abschliessende Erklärung geben, sondern lediglich Möglichkeiten zeigen, teils wiederum als Perspektive für spätere Mitteilungen, teils aber und vornehmlich um die vielseitigen Gesichtspunkte darzutun, die sich aus jenen Tatsachen ergeben können.

1. Inhibition a uf Reflexe. Wenn man die Bahnen mit schwachen Strömen reizt, so erzielt man Kontraktion, abwechselnd mit Erschlaffung; reizt man mit stärkeren Strömen, so erfolgt generelle Kontraktion mit Inhibition eines jeden Rhythmus. Dass der tonisch oder auf Erregung hin koutrahierte Schneckenmuskel rhythmische Bewegungen nicht auszuführen vermag, dass also Kontraktion auch Ursache der Inhibition sein kann, das habe ich an Aplysia gezeigt. Aus dieser Tatsache erklärt sich ein Reflex, den man bei Helix im Freien beobachten kann: Man sieht nicht selten eine kriechende Helix, vor der man vorbeigeht, zurückfahren und hierdurch im Kriechen innehalten.

2. Barynogene Polyrhythmie: Straub ${ }^{1}$ ) (S. 444 ff.) hat am Aplysienherzen gefunden, dass zum Zustandekommen der rhythmischen Tätigkeit ein bestimmter minimaler Füllungsgrad (Dehnung, Belastung) Voraussetzung ist, und dass mit zunehmender Belastung der Rhythmus an Schnelligkeit zunimmt. Straub gibt zur Erklärung dieser Erscheinung eine Vermutung. Er stützt sich auf die bekannte Auffassung von E. Hering, dass nämlich Kontraktion ein Dissimilationsvorgang, Erschlaffung aber Assimilation sei. Bei einem gewissen Grade erreicht die Erschlaffung einen "kritischen Punkt", wo explosivartig die Dissimilation erfolgt. Eine „barynogene Polyrhythmie" würde sich auch auf Grund der uns nunmehr bekannten Tatsachen eroeben, und es scheint mir vou besonderer Wichtigkeit zu sein, dass wir haben zeigen können, dass die höhere Leistung des gedehnten Muskels nicht, oder doch nicht vornehmlich seinem inneren Zustande, vielmehr dem ihn bedingenden Zustande im

1) Walter Straub, Fortgesetzte Studien am Aplysienherzen (Dynamil, Kreislauf und dessen Innervation) nebst Bemerkungen zur rergleichenden Muskelphysiologie. Pflüger's Arch. Bd. 103 S. 429-449. 
Nervensystem zuzuschreiben ist. Anf alle Fälle aber haben wir barynogene Mehrleistung erzielt in Fällen, bei denen der "Assimilationsgrad" des Muskels gar nicht verändert war (Halbtierversuch; vgl. auch Teil III). Auch die Bezeichnung, „barynogen" ist, wie mir nach meinen Erfahrungen scheint, nicht einwandfrei, und zwar insofern, als sie sich nur auf einen Sonderfall bezieht, ohne jedoch die unmittelbare Ursache der Erscheinung, den Tonus, zu berühren. Mit demselben Rechte könnte man von thermogener, alkaloidogener (an der cerebrallosen Aplysia von mir hervorgerufen) Polyrhythmie reden, alles doch nur Variationen der nämlichen Erscheinung. Ich denke, es bandelt sich hier um generelle Gesetze, die, wenn sie in der glatten Lokomotionsmuskulatur Gültigkeit haben, für die gleichbeschaffenen Herzmuskelfasern auch als zutreffend in Anspruch genommen werden dürfen ${ }^{1}$ ).

3. Die Tatsache, dass die Erregbarkeit der Schneckenmuskulatur von einer Anzahl verschiedener Faktoren abhängt, scheint mir im Gegensatz zu stehen mit der Angabe bestimmter, absoluter, auf die Erregbarkeit bezogener Zahlen, die von beiden Lapicque ${ }^{2}$ ) angegeben werden; z. B. die Zeit, die ein konstanter Strom, bestimmter minimaler Intensität braucht, um die Muskeln einer Helix zu erregen, beträgt 0,048", für Aplysia 0,8". Selbstverständlich hege ich diesen Angaben gegenüber an und für sich keinen $Z$ weifel, doch scheint es mir, als seien die Forscher hierbei ganz abhängig vom zufälligen Stande des Tonus im Muskel, der sich unter den von ihnen gewählten Bedingungen konstant gezeigt haben mag. Aber einen absoluten Nullpunkt kennen wir für diesen Tonus nicht. Es wäre interessant unter Berücksichtigung des Gesagten die Ergebnisse der beiden Lapic que nachzuprüfen, da ibre Versuchsanordnung sich immerhin wesentlich von der unserigen unterscheidet.

4. Tropismen und Anhydrobiose. Sehr interessant im Lichte der im experimentellen Teile angegebenen Tatsachen erscheinen wir einige Befunde von G. Bohn zu sein ${ }^{3}$ ), Dieser Forscher

1) Vgl. hierzu auch: E. Th. Brücke, Zur Physiologie der Kropfmuskulatur von Aplysia depilans. Pflüger's Arch. Bd. 108 S. 192-215. 1905.

2) L. Lapicque et $\mathrm{Mm}^{\mathrm{m}}$ Lapicque, Durée des processus d'excitation pour différents muscles. C. R. Acad. Sc. Paris t. 140 p. 801-804. 1905.

3) Georges Bohn, L'anhydrobiose et les tropismes. C. R. Acad. Sc. Paris t. 139 p. 809-811. 1904. Vgl. weitere Publikationen des gleichen Forschêrs in C. R. Soc. Biol. Paris, z. B. t. 57 p. 365-367. 1904. 
findet nämlich, dass bei einer Küstenschnecke (Littorina) je nach Wassergehalt der Gewebe der Phototropismus anders gerichtet ist.

Hier handelt es sich offenbar um eine spezielle Anpassung der Tiere an ihr Küstenleben mit Ebbe und Flut, und es liegt im Wesen aller speziellen Anpassungen, dass sie sich auf Grund allgemeiner Gesetze - in der Regel wenigstens - ohne besondere Analyse nicht rekonstruieren lassen (wenn man wenigstens kein Freund von Hilfshypothesen ist). Immerhin liegt hier eine Erklärungsmöglichkeit auf Grund des Antagonismus der beiden grossen Regulatoren der Bewegung vor: des Tonus - der durch mehr oder weniger grossen Wasserdruck ja verändert wird - einerseits, und des Cerebralganglion mit den Photorezeptoren andrerseits; all dies auf Grund spezieller Anpassung, die kaum schwierig zu ermitteln sein dürfte. Jedenfalls scheint mir eine derartige Hypothese mehr Anspruch auf Wahrscheinlichkeit $\mathrm{zu}$ haben als diejenige, die $\mathrm{Bohn}$ selbst aufstellt. Dieser Forscher glaubt nämlich seine Zuflucht zu dem mehr oder weniger rätselhaften Begriffe "Anhydrobiose" nehmen zu inüssen. Ich werde auch auf diese Frage, wenn auch nicht gerade für Littorina, zurückkommen.

5. Die pharmakologische Bedeutung einiger mitgeteilter Versuche. Zum Schlusse dieser Einzelbetrachtungen möchte ich noch auf die pharmakologische Bedeutung einiger Tatsachen hinweisen, ohne dass ich mich natürlich in die neueste pharmakologische Literatur einlesen könnte, um das Nene mit Bekanntem zu vergleichen.

Wir haben gesehen, dass innerhalb einer Schnecke Kokain in vierfacher Weise auf die Erregbarkeit einwirken kann, und dass dies nicht so sehr an der Mannigfaltigkeit der Eigenscbaften jenes Alkaloids, als vielmehr an den differenten Teilen des Zentralnervensystems selbst liegt. Denn ich glaube, der Nachweis ist mir zu erbringen gelungen, dass Kokain, wenn es einmal eingedrungen ist und die in Frage kommenden Erscheinungen hervorruft, nicht erst eine erregende, später eine lähmende Wirkung habe. Jene Wirkungen aber waren: 1. auf die Pedalganglien: a) geringe Lähmung: gesteigerte Erregbarkeit (geminderter Tonus), b) vollkommene Lähmung: geminderte Erregbarkeit (gesteigerter Tonus); 2. auf das Cerebralganglion: a) geringe Lähmung: geminderte Erregbarkeit, b) vollkommene Lähmung: ge steigerte Erregbarkeit. Eine Wirkung auf den Tonus lässt sich nicht nachweisen. 
Auffallend ist auch, dass das Alkaloid in relativ sehr kurzer Zeit die Ganglien zu durchdringen scheint: Trotz der primitiven Art der Applikation ist der Effelt in der Regel ein recht eindeutiger. (Von der wahrseheinlich osmotischen Wirkung ganz zu Beginn des Versuches sei hierbei abgesehen.) Ob aus diesen Tatsachen allgemeine Schlüsse zu ziehen sind, ist zu entscheiden nicht meine Sache.

\section{Die kausale Betrachtungsweise der Ergebnisse.}

Ich will vorausschicken, dass ich durchaus nicht die Absicht habe, jede einzelne Mitteilung mit einer vollständigen bypothetischen Synthese zu belasten. Eine solche Hypothese ist am Platze, wenn alles Material, welches man derzeit zu bieten in der Lage ist, erschöpft ist. So weit aber sind wir noch nicht. Meine Absicht ist, nur dasjenige anzugeben, was wir unmittelbar aus den Versuchsergebnissen über das Wesen der Erscheinungen, d. i. den Kausalzusammenhang innerhalb dieser, ableiten können.

\section{A. Was lernen wir über das Wesen des Muskeltonus?}

In Mitteilung I habe ich versucht, über das Wesen des Muskeltonus zwei gegensätzliche Hypothesen aufzustellen: Entweder der Muskeltonus ist ein rein muskulärer Zustand, etwa ein mehr oder weniger weitgehender Grad von Koagulation, erzeugt durch Erregung vom Nervensystem aus, und gelöst durch einen zweiten, gleichfalls zentrifugalen, in seiner Wirkung jedoch konträren Impuls. Die Dynamik eines solchen Muskels bestünde dergestalt nur in einem einzigen Akte: Zusammenziehen auf Erregung. Der Widerstand gegen die Ausdehnung ist ganz unahhängig vom eigentlich dyuamischen oder, sagen wir, stoffverbrauchenden Apparate und vor allem von demjenigen Nervenvorgang, der die Verkürzung erzeugt hat. Er verhält sich zur Muskeltätigkeit wie eine von der Maschinenkraft durchaus unabhängige Bremse zu jener.

Die zweite Hypothese fasste den Tonus ebenfalls als eine Art Bremsvorrichtung auf, möglicherweise ja auch als Koagulationszustand seines Plasmas, doch in einer Weise, dass dieser Zustand nicht unabhängig sei von dem Nervenvorgang, der ihn ins Leben rief. Der Zustand im Nervenapparate, demzufolge die Verkürzung eingetreten ist, muss (als statisches Potential) beibehalten werden, soll anders der Muskelzustand sich nicht verändern. Minderung des Potentials bedeutet proportionale Erschlaffung im Muskel. 
Es ist also Hypothese I an eine bestimmte Vorstellung vom Verhältnisse zwischen Tonus und Erregung gebunden: Der Tonus wird durch Erregung ins Leben gerufen, er ist selbst die, nach Erregung beibehaltene, durch sie bedingte Veränderung im Muskel. Demnach gibt es auch nur eine Form aktiver Muskelverkürzung.

Hypothese II spricht von Erregung überhaupt nicht. Ich will hier (hypothetisch) hinzufügen, dass der nervöse Vorgang, der den Tonus bedingt, nicht identisch sei mit demjenigen, der Erregung zu nennen ist.

Diese letzte Frage ist es, die uns naturgemäss für diesmal zu beschäftigen hat. Welche Vorstellung vom Verhältnis zwischen Tonus und Erregung lässt sich mit den Tatsachen in Einklang bringen?

Hypothese I: Jede Zusammenziehung eines Muskels tritt nur auf Erregung ein; Tonus ist der rein mechanisch beibehaltene, durch die Erregung verursachte Zustand im Muskel, zu dem aber ein proportionaler Zustand im Nervenapparat nicht existiert.

Wir kommen auf unsere Fragestellung Teil I A zurück und überlegen das Folgende: Wir nehmen an Muskel $A$ habe Länge 1, und dieser Länge entspräche der Koagulationsgrad $\alpha$, seinerseits erzeugt durch die Erregungsintensität $i$. Muskel $B$ besitze Länge 2, entsprechend einem Koagulationsgrade $\alpha-n$, entsprechend einer Erregungsintensität $i-m$. Voraussetzung ist; dass beide Muskeln gleiche und, proportional zur Verkürzung, in gleicher Weise sich verändernde Last tragen; dass ferner im Koagulationsgrade $=0$ beide Muskeln gleich lang sind.

Bei Muskel $A$ wird $i$ natürlich eine neue Reaktion nicht hervorzubringen vermögen, da $i$ der Koagulationsgrad $\alpha$ und eben nicht $x>\alpha$ entspricht. Hingegen wird $i$ genügen, den Zustand von Muskel $B$ zu verändern, solange nämlich, bis dieser $=\alpha$ wird. Ist dieser Zustand einmal erreicht, so sehe ich keinen Grund ein, warum $i$ auf zwei Muskeln, die nunmehr durchaus die gleichen inneren Bedingungen bieten, verschieden wirken soll.

Das Gesagte wird noch deutlicher, wenn von vornherein $n=0$ ist, d. h. also, wenn Muskel $A$ und Muskel $B$ im gleichen Zustande verkehren: sie bei gleicher Länge den gleichen Widerstand gegen die gleiche Last bieten. Auf die zweite Hälfte des Tieres, dem Muskel $B$ zugehört, haben wir eine Last wirken lassen, aber im Muskel $B$ ist keine Reaktion erfolgt; also geht uns nach Hypothese I 
der Eingriff überhaupt nichts an. Denn einen dem Tonus entsprechenden, ihm (in etwa) proportionalen Zustand des Nervensystems gibt es ja nicht, und dass jene Belastung keinen Reflex auslöst, die sich mit dem künstlichen Reize des Experiments summiert, lässt sich leicht zeigen: Unter Annahme von Hypothese I, haben wir nämlich in Mitteilung I gesehen, muss unser Eingriff (die Belastung der einen Tierhälfte) einen Reflex bedingen, bei dem vornehmlich das hem mende System in Tätigkeit tritt, da ja Tonusfall (unter ganz unwesentlich veränderten Bedingungen) die Haupterscheinung ist, die wir nach Belastung der einen Tierhälfte uachweisen können: Ein erregender Reflex ist also sicherlich ausgeschlossen.

Mit allen diesen Überlegungen und Postulaten stehen die Tatsachen in vollständigen Widerspruch: Stets kann sich unter strikter Innehaltung aller obiger Bedingungen Muskel $B$ über die Länge des Muskels $A$ hinaus zusammenziehen.

Auch nach Hypothese II darf der Nervenvorgang, der den tonischen Verkürzungsgrad bedingt, nicht identisch sein mit demjenigen, den wir Erregung nennen; denn dann würde mit der Kontraktion auf Erregung, die Steigerung des Tonus auch hier Schritt halten, und wenn $B$ die Länge von $A$ erreichte, so würde $B$ gegen den nämlichen Reiz gesperrt sein als $A$. Dieser Satz gilt, ob sich nun die Erregung gleichmässig auf $A$ und $B$ verteilt, oder aber, ob die Erregung dem von uns für den Tonus schon angenommenen Energiegesetze folgt, also sich ganz nach dem locus minoris resistentiae wendet. Sind beide Muskeln gleich lang geworden, unter obiger Annahme, so verteilt sich die Erregung eben wieder gleichförmig. Auf die Frage nach dem Ausgleichgesetze komme ich in dieser Mitteilung noch, wenn auch für diesmal nur ganz kurz, zurück. Dies wird ganz anders, wenn $B$ durch Erregung so kurz werden kann als $A$, ohne dadurch den gleichen Tonusgrad zu erhalten; dann würde nichts dagegen sprechen, dass $B$ sich über die Lage von $A$ hinaus zusammenzöge. Dieser Voraussetzung aber kann Hypothese II genügen, da sie ja über das Verhälnis zwischen Muskeltonus und Erregung gar nichts präsumiert.

Gehen wir - nach diesem indirekten - zum direkten Beweise der These über, dass der Tonus, der Zustand also, der die Erregbarkeit beeinflusst, 1. nicht ausschliesslich (wie Hypo- 
these I dies verlangt) dem Muskel angehörte, sondern auch (als Zustand) dem Nervensystem, und dass er 2. nicht identisch sei mit demjenigen Zustande, den Erregung erzeugt. Den Beweis von Teil 1 der These habe ich weiter oben schon angedeutet; er sei hier nun definitiv ausgeführt. Am deutlichsten lässt sich dies wiederum an der Hand des Halbtierversuches tun: Muskel $A$ und $B$ sind bei unseren Versuchen identisch. Die verschiedenen Bedingungen, Belastung und Nichtbelastung der anderen Seite, verändern sie gar nicht. Hier lässt sich nun zeigen, dass das Nervensystem einen veränderten Zustand aufweist. Befindet sich der registrierende Muskel unter „Hochbelastung.", so sinkt in ihm auf Belastung der anderen Seite der Tonus dergestalt, dass der Zejger unseres Apparates um mehrere Gramm fällt. Je geringer nun die Belastung des registrierenden Muskels wird, um so geringer wird auch jene Reaktion, bis sie schliesslich praktisch gleich Null wird. Was haben wir nun unter "Hoch"bezw. "niederer Belastung" zu verstehen? Ein umgekehrtes Verhältnis im Tonus ${ }^{1}$ ) zwischen System I. Ordnung und Pedalganglien. Denn trennt man bei Hochbelastung das Pedalganglion ab, so sinkt der Tonus; der gleiche Eingriff unter niederer Belastung bedingt im Gegensatze hierzu Stejgen des Tonus. Nun lehrt der „Halbtierversuch" also, dass, solange die Muskulatur (oder, wohl richtiger, der zugehörige Nervenendapparat) ihre Energie zum Widerstande gegen die Last vom Pedalganglion bezieht (Hochbelastung), Schädigung des energetisehen Zustandes im Pedalganglion gleichbedeutend ist mit Schädigung des Widerstandes im Muskel. Ist jedoch der Widerstand im Muskel an sich ein grosser, so dass er vom Pedalganglion dauernd gemindert werden muss (weil es geringeren Tonus hat, damit der Innendruck nicht zu hoch wird), verfügt also das ganze System (I. Ordnung + Pedalganglion) über ausreichende Energie, so brawcht es den durch den belasteten Muskel beanspruchten Tonus nicht allen Teilen des Systems zugleich zu entnehmen. Es herrscht also wohl das Gesetz vom Ausgleiche, aber mit Dekrement, welch letzteres nicht dem Leitungswiderstande (dieser wird ja durch Belastung nicht verändert), sondern unbekannten „Vorrichtungen" im Ganglion zuzuschreiben ist ${ }^{2}$ ). Es muss nach alledem

1) Das Wort „Tonus" wird hier, nach v. Uexküll, auch für den entsprechenden Zustand innerhalb des Nervensystems verwandt.

2) Wenn wir für den Tonus ein absolutes Mass besässen, so würde sich das nach meiner Überzeugung leicht beweisen lassen: Die Belastung der einon 
in unserem Experimentalfalle, bei dem also der Zustand im Muskel unverändert bleibt, der Zustand im Nervensystem nach Belastung der anderen Hälfte ein veränderter sein, da es sonstgar nicht einzusehen wäre, warum nach Hochbelastung des registrierenden Teiles dieser nunmehr reagieren solite. Bei niederer Belastung erstreckt sich dieseVeränderung nur eben nicht (oder doch nicht in nachweisbarem Grade) auf den Muskel.

In beiden Fällen kreise also ein "Erregungsstrom" in diesem Nervensystem. In einem Falle $(A)$ bedingt er schwächere, im anderen Falle $(B)$ aber stärkere Reaktion. Am Muskel kann es nicht liegen, denn er ist derselbe unter gleichen äusseren und inneren Bedingungen. Die Sperrung der Erregungsleitung muss für unseren Fall ausschliesslich imı Zustaude des Nervensystems gesucht werden. Und übertragen wir dies nun auf normale Verhältnisse, bei denen mit der Zustandsänderung im Nervensystem eine Längenänderung im Muskel einhergeht, bei denen aber alle angegebenen Erscheinungen qualitativ unverändert auftreten, so finden wir: Gewiss ist vom Muskeltonus die Erregbarkeit abhä̀ngig, allein vorab nur insofern, und nur weil er proportional ist und Hand in Hand sich verändert mit Zuständen im Zentralnervensystem. Hand in $\mathrm{H}$ and, das heisst aber, wie jetzt kaum mehr zweifelhaft sein düfte: durch bipolaren Ausgleich. Es ist natürlich durchaus nicht ausgeschlossen, dass der dergestalt beringte Muskelzustand, auf rein muskulärer Basis, seinerseits dazu beiträgt, Erregbarkeit und Arbeitsleistung zu vergrössern; dies ist eine Frage, der wir nicht nähertreten wollen.

Teil 2 unserer These, dass nämlich Tonuszunabme und Kontraktion auf Erregung nicht dasselbe sei, können wir gleichfalls experimentell stützen:

1. A u f negativem Wege. Es ist nämlich ein grosser Unterschied, ob wir einen Muskel belasten und die Zeit bestimmen, die er braucht, sich um ein bestimmtes Gewicht zu entlasten, oder ob wir nach seiner Entlastung den nämlichen Muskel, obne irgend etwas

Tierhälfte ist relativ sehr hoch; ihr entspricht unter allen Umständen im registrierenden Teil nủr ein verbältnismässig geringer Fall, vor allem nur gering gesteigerte Erregbarkeit. In der Natur dürfte das Dekrement, wenigstens beim Ausgleichen des Tonus innerhalb der Gesamtmuskulatur, kaum eine Rolle spielen, da derartige Differenzen, wie wir sie erzeugen, nie in Betracht kommen dürften. 
zu verändern, reizen, bis er die nämliche Maximallast trägt. Nunmehr wird die zur gleichen Entlastung benötigte Zeit eine wesentlich kürzere sein: Tonischer Verkürzungszustand und Verkürzung auf Erregung sind nicbt ideutisch. Beleg:

Tabelle 36.

Normales Tier, wird mit 15 g belastet, und die Zeit bestimmt, die es braucht, um sich auf $5,2 \mathrm{~g}$ zu entlasten.

\begin{tabular}{|c|c|}
\hline Zeit & Belastung \\
\hline $\begin{array}{l}10 \mathrm{~h} 5^{\prime} \\
10 \mathrm{~h} 28^{\prime}\end{array}$ & $\left.\begin{array}{c}15 \mathrm{~g} \\
5,2 \mathrm{~g}\end{array}\right\} 23$ Minuten \\
\hline
\end{tabular}

Das Tier wird gereizt (Wechselströme), bis der Zeiger $15 \mathrm{~g}$ anzeigt.

$\left.\begin{array}{c|c}10 \mathrm{~h} 50^{\prime} & 15 \mathrm{~g} \\ 10 \mathrm{~h} 52^{\prime} & 5,2 \mathrm{~g}\end{array}\right\} 2$ Minuten

Der während der Kontraktion stattfindende Teil des "Restitutionsprozesses" ist in Aubetracht des enormen Unterschiedes zwischen tonischer und Firegungskontraktion ganz und gar zu vernachlässigen. Nach Exstirpation des Cerebralganglion werden zur gleichen Strecke 1 Minute, nach Exstirpation aller Ganglien 21/2 Minuten gebraucht.

Neben dem bereits angegebenen Resultate zeigt der Versuch, dass auch in der Ausdehnung, die auf Erregungskontraktion folgt, der Tonus noch eine Rolle spielt, eine Rolle, die den uns bekannten Gesetzen folgt (Verminderung durch Kontraktion, Steigerung nach Exstirpation der Pedalganglien), dass aber - und das ist für uns das Hauptresultat - der hierdurch erzielte Widerstand gegen das Gewicht in gar keinem Verhältnis steht zum ursprünglichen Widerstand: Tonische Verkürzung und Verkürzung auf Erregung sind nicht identisch.

2. Während der Kontraktion auf Erregung unter den Bedingungen, die unser Apparat stellt, stets Ausdehnung folgt, ist dies nicht der Fall bei der Verkürzung im registrierenden Muskel, welche der Entlastung der anderen Tierhälfte folgt.

3. Weder diese Verkürzung noch eine solche die, wir nach Entlastung eines registrierenden Muskels selbst erhalten, untersteht der Regulation des Cerebralganglion, welches allein unmittelbar Verkürzung auf Erregung hin zu regulieren vermag, sondern dem Pedalganglion, wie dies vor allem die Versuche mit Eingriff am registrierenden Muskel selbst gezeigt haben. Das Pedalganglion aber 
reguliert unmittelbar nur den Tonus. Es gäbe keinen Grund, einzusehen, warum tonische Verkürzung nicht auch dem Cerebralganglion unterstellt wäre, wenn sie nümlich mit Verkürzung auf Erregung identisch sein würde. Also müssen wir auch hiernach annehmen, dass Verkürzung als Tonusschwankung und Verkürzung auf Erregung verschiedenartige Erscheinungen seien.

Allen diesen Tatsachen vermag Hypothese I nicht zu genügen. Fassen wir sie zusammen: Grössere Frregbarkeit des tonusarmen Muskels ist nicht abhängig vom (Koagulations-)Zustande des Muskels, sondern vom mehr oder minder aktiven Zustande im Nervensystem: Für Hypothese I ist Tonus überhaupt nur (Koagulations-)Zustand des Muskels; einen mit ihm verknüpften aktiven Zustand des Nervensystems kennt sie nicht.

Neben der aktiven Verkürzung auf Erregung gibt es eine solche als Tonusschwankung: Für Hypothese $I$ ist Tonusschwankung ein Wechselspiel von Erregung und Hemmung; sie kennt nur und kann nur kennen: Verkürzung auf Erregung.

Vor allem aber ist Hypothese I nur möglich, wenn das Vorbandensein zentrifugaler Hemmungsnerven nachgewiesen werden kann: Das lokomotorische System der Schnecke besitzt keine solche.

Kurz, ich sehe mich nicht mehr in der Lage, Hypothese I, das ist die „Unipolarhypothese“", in ihrer Anwendung auf die Lokomotion der Schnecke als möglich anzuerkennen, und ich muss es ihren Anhängern überlassen, weiter für sie einzutreten. Ich erkläre, sie unmittelbar wieder zu den möglichen Annahmen zählen zu wollen, wenn es gelingt, sie mit den Tatsachen in Einklang zu bringen oder eine ähnliche, Hypothese II gegensätzliche zu ersinnen, für die dieses gilt. Ich wiederhole aber meine Bitte, hierbei auch alle Tatsachen und Argumente berücksichtigen zu wollen.

B. Die Erregbarkeit ist regulierbar durch mehr oder weniger aktiven Zustand der Ganglien: Das Gesetz vom Energieausgleich.

Die Frage, was Nerventonus, was Erregung sei, soll uns noch nicht beschäftigen; wir werden uns hier auf die Erörterung der Gesetze beschränken, denen diese Energieformen gehorchen. Wir haben schon für den Tonus und seine Regulierung gesehen, dass wir das Pedalganglion keineswegs aussehliesslich als eine bessere und 
sicherere Verbindung zwischen verschiedenen Punkten der Peripherie zu betrachten haben, sondern als einen Körper, der selbst über ein gewisses statisehes Potential derjenigen Energie verfügt, die mittelbar den tonischen Zustand im Muskel bedingt. (v. Uexk üll benutzt die Bezeichnung "Reservoir"; speziell da, wo es sich um Tonusregulierung handelt: „Repräsentant" - eine sehr glücklich gewählte Bezeichnung). Die Beziehung aber, die zwischen dem Pedalganglion einerseits und dem System I. Ordnung andrerseits besteht, lässt sich als "Gesetz vom Tonusausgleich" bezeichnen, wie wir das hinlänglich oft gesehen haben. Ganz gleich liegen die Verhältnisse für die Erregung, solange wir sie unabhängig vom Tonus betrachten. Das Cerebralganglion absorbiert ständig einen Teil der Erregung, die im System I. Ordnung (oder diesem System + Pedalganglion) zirkuliert, und tut dies gleichfalls nach dem Gesetze vom Ausgleich, welches ja alle leitbaren Energieformen beherrscht. (Man denke hier nur an die Stromverteilung in einem komplizierten Leitungsnetz oder an die Wasserverteilung in einem Kanalsystem mit fliessendem Wasser usw.) Je geringer also der aktive Zustand im Cerebralganglion ist, desto höher ist seine Fähigkeit, Erregung zu absorbieren (Kokain), und umgekehrt: steigt der aktive Zustand, so vermindert sich jene Fähigkeit (Kochsalz), bis sie gleich Null wird, ja vielleicht auch bis positive Erregung abgegeben werden kann - ein Verhalten, für das wir im Pedalganglion gleichfalls ein Analogon besitzen. „Hemmungsnerven " konnten durch genau die gleichen Versuche und Argumentationen (vor allem Reizung unter Kokainwirkung) wie beim Pedalganglion ausgeschlossen werden. Ich lasse es dahingestellt, ob bei Leitung der Erregung eine Bipolarität in Frage kommt, wie eine solche mit Bestimmtheit für die Leitung des Nerventonus anzunehmen ist: Die Erregung läuft von den Rezeptoren auf zentripetaler Babn zu den Pedalganglien ${ }^{1}$ ), von da zum Muskel oder, wenn der Widerstand nicht zu gross ist (verglichen mit dem Widerstand in den Nervenenden wahrscheinlich, oder in Teilen des Pedalganglion - Tonus), ganz oder teilweise zum Cerebralganglion, wo sie ganz oder teilweise ausgeglichen oder sonst vernicbtet wird.

Mit anderen Worten: das universelle Gesetz vom Ausgleiche, oder, wie man auch sagen könnte: das Ge-

1) $\mathrm{Zu}$ den Pedalganglien nur, weil der Widerstand in den Bahnen geringer ist als in den Netzen! 
setz loci minoris resistentiae, gilt auch für die Erregung, nur mit dem Unterschiede (verglichen mit dem Tonus), dass die Erregung am Orte ihrer Betätigung vernichtet wird, so dass in den von uns beobachteten Fällen eine bipolare Leitung dieser Energieform nicht in Frage kommt. In welchem Verhältnisse der aktive Zustand des Cerebralganglion zu demjenigen des Pedalganglion steht, darüber können wir höchsters Vermutungen hegen, diese aber hier wiederzugeben, wäre überflüssig, solange wir eben noch experimentieren können.

Auf alle Fälle dürfen wir jetzt schon sagen: Der Nerventonus ist die statische Form irgendeiner Energie ${ }^{1}$ ). Die Erregung aber ist die dynamische Form irgendeiner Energie, da für sie einige wichtige Gesetze, die in der Dynamik aller leitbaren Kräfte Gültigkeit haben, sich bestätigen. Was liegt näher als anzunehmen, dass Tonus und Erregung jene beiden Erscheinungsformen ein und derselben Energie sind? (v. Uexküll). Wir haben ja oft genug Gelegenheit gehabt zu sehen, dass beide einander beeinflussen: Sicherlich beeinflusst der Tonus die Erregung; aber auch umgekehrt geht Kontraktion auf Erregung hin, nicht spurlos am Tonus der Muskulatur vorbei. Ich erinnere nur an den bereits erwäbnten, wenn auch noch nicht durchgeführten Begriff: "Tonusladung", der Erscheinung also, dass unter gewissen Bedingungen (die ich später mitteile) der Tonus im Muskel auf Erregung um kleine Werte zunimmt, die allerdings in gar keinem Verbältnis zu den durch Erregung unmittelbar hervorgerufenen Kontraktionszuständen stehen. Erst wenn wir über alle diese Punkte durehs Experiment Klarheit gewonnen haben, erst dann wollen wir zum vollen Ausbau der Hypothese übergehen und zur Vergleichung unserer Resultate mit denjenigen von v. Uexküll und anderen Forschern. Ich will aber hier schon bemerken, dass ich erst nach längerer Zeit diese Resultate der Öffentlichkeit zu übergeben in der Lage sein werde.

Mit dieser Arbeit also betrachte ich die eigentlichen Vorstudien zu einer Untersuchung über die spezielle Mechanik der Lokomotion als abgeschlossen, eine Untersuchung, an die wir jetzt wenigsters

1) Dass der Tonus unbedingt eine Flüssigkeit sein muss, wie v. Uexküll meint, davon habe ich mich noch in keinem Falle überzeugen können, da, wie schon angedeutet, es keine leitbare Energie gibt, die sich unter gleichen Bedingungen anders verhalten würde! 
mit dem nötigsten Materiale ausgerüstet herantreten können. Aber auch in theoretischer Hinsicht war - so hoffe ich - diese Voruntersuchung nicht unfruchtbar. Möge sie eine Kleinigkeit mit dazu beigetragen haben im Kampfe gegen die Anschaung, dass die Zentren nichts seien, als Knotenpunkte zahlreicher Leitungsbahnen. Gewiss ist das eine ihrer wichtigsten Aufgaben; vor allem aber sind sie "Reservoirs" von Energie, die auf Grund ihres mehr oder weniger hohen Potentials das ihnenunterstellte Nervenmuskelsystem in seiner automatischen Funktion zu leiten vermögen, nach dem universellen Gesetze vom Energieausgleich - bei den Schnecken vor]äufig. 